(C) 2018. This manuscript version is made available under the CC-BY-NC-ND 4.0 license http:// creativecommons.org/licenses/by-nc-nd/4.0/ 


\title{
Improving power sharing in islanded networked microgrids using Fuzzy-based consensus control
}

\author{
Mohsen Eskandari ${ }^{1}$ eskandari.mohsen@ymail.com; Li Li ${ }^{1}$; Mohammad. H. Moradi ${ }^{2}$ \\ ${ }^{1}$ Faculty of Engineering and Information Technology, University of Technology Sydney, Australia. \\ ${ }^{2}$ Dept. of Electrical Engineering, Bu-Ali Sina University, Hamedan, Iran
}

\begin{abstract}
The rising world-wide trend toward developing clean energy resources has caused dispersed installation of renewable energy resources (RESs) in distribution grids. Microgrid (MG) concept is proposed as a key factor in optimal and secure integration of, mostly converter-based, RESs into power systems. One of the major challenges related to MG control is ineffectiveness of droop control in accurate power sharing which is affected by the feeder impedance. In this paper, a fuzzy-based consensus control protocol is developed to address this issue in multi-bus MGs (MBMGs). Consensus signals are inserted into the conventional droop controller as complementary part to overcome the drawback of the droop control in power sharing in MBMGs. Dynamic fuzzy coefficients of consensus signals are designed to model $X / R$ ratio of the grid impedance in the control system. In addition, a novel small signal model of MBMG is developed, by considering the conventional droop control, MBMG power network and power lines impedance to design and assess performance of the control system. Consensus control is also incorporated into the proposed control system of MBMG to analyze the stability. Simulation results are presented to assess effectiveness of the control strategy in MATLAB $\backslash$ Simulink.
\end{abstract}

Index Terms - Consensus Control; Power System Dynamic Stability; Fuzzy Control; Microgrid; Power Sharing; Small Signal Model;

\section{Introduction}

Global warming and environment concern have caused a world-wide trend toward using clean natural resources. In contrast to conventional power plants, renewable energy resources (RESs) are installed in power systems inherently in a distributed manner [1]. This causes a great revolution in power systems in terms of control and energy management. Microgrid (MG) has been introduced as a promising solution to adapt the conventional control strategies in the coming restructured modern power systems. In addition, MG concept provides extra benefits for consumers, by autonomous operation capability, which enhances the system reliability and energy efficiency by developing energy management system among distributed generation (DG) units and loads [2]-[3]. The MG concept is implemented by means of a hierarchical control system consisting of three control levels [4]-[5]: 
- Tertiary level or MG central controller (MGCC), coordinated with upstream grid, responsible for scheduling and energy management [6]-[7].

- Secondary level for power quality improvement [8]-[9].

- Primary level for power sharing and voltage regulation while securing the stable operation of MG [10]-[11]. The primary level, which is the case in this work, involves the technical aspect of the control system from the power engineering point of view and plays an important role in proper operation of MGs, especially in the islanded mode [12].

DG units are connected to the MG through the voltage source inverters (VSIs) to provide AC voltage at the power network side [13]. Due to the inherently distinct features of VSIs with conventional synchronous generators, a novel control strategies are required for power sharing and voltage regulation. Nevertheless, power engineers conservatively seek to employ traditional droop control scheme, which works well in bulk power systems, for the primary level in MGs [14]. The $f-P$ droop control loop, which mimics the behavior of synchronous machines, has been proposed, for active power sharing among DG units in MGs [15]-[16]. The $V-Q$ droop loop is also proposed for voltage regulation in MGs and also to distribute reactive power among DG units proportional to droop gains [13]. Droop control, with easy implementation, obviates high band-width communication network requirement and provides plug-and-play capability in MGs [17]. However, there are some problems in relation to this control system which should be addressed properly:

1) in conventional power systems, active power is controlled by frequency (rotor speed) because of the nature of synchronous machines and inductive impedance of transmission lines (high $X / R$ ratio). While in MGs, the X/R ratio of grid impedance is not as high as in transmission grids, sometimes even less than one, which disarranges the frequency $f$ $P$ and $V$ - $Q$ control loops. In this regards, some works adopted $V-P(f-Q)$ droop (boost) control loops in low voltage MGs in which the power network impedance is dominantly resistive [18]-[19]. Nevertheless, there is a cross-coupling between either the $f-P$ and $V-Q$ droop loops or $V-P(f-Q)$ droop (boost) control loops in MGs where the $\mathrm{X} / \mathrm{R}$ ratio is normally around one;

2) in the power converter-based MGs, the active power is linked to the DC bus voltage, which is completely different with conventional synchronous generators. This is because of the slow response of primary micro sources, like fuel cell and micro turbine, to the output active power variation and load tracking. This, in turn, leads to voltage drop in the DC bus, which inspires some researchers to adopt $V_{d c}-P$ droop loop for power sharing [20]. The DC voltage drop impact increases the modulation index over the maximum permitted value, which leads to voltage distortion in the AC side [21]. Consequently, distributed (installed on the DC bus) or concentrated energy storage units like battery or super-capacitors are proposed, as spinning reserve, to compensate slow response of micro sources [2], [10], [21]. 
3) the strategy in bulk power systems for voltage regulation is to retain voltage at the nominal value at generation buses through automatic voltage regulator (AVR) and at load buses through reactive power compensators. However, due to low impedance of the feeders in MGs, a small error in voltage regulation leads to circulating reactive current among VSIs. Besides, compensators do not work at unit power factor, which makes the power network exposed to resonance at industrial sites. Therefore, DG units are responsible for supporting reactive power as well as voltage regulation in MGs. To this end, the $V-Q$ droop loop is used for reactive power sharing implementation. However, voltage drop over the feeder impedance makes the reactive power sharing inaccurate, which may impose small scale power converters to overcurrent conditions and cause circulating reactive current among DG units [22];

The insufficiency of droop controller in accurate power sharing in MGs has encouraged researchers to develop an effective method to implement power sharing precisely. The literature related to this issue could be divided into two main categories, which will be briefly introduced next.

The first group of papers, which published from the early introduction of MGs till now, have addressed the accurate power sharing issues and presented stability analysis in simple parallel inverter-based MGs [22]-[29]. A control strategy based on adaptive virtual impedance is developed in [27] to have accurate reactive power sharing in islanded microgrids. DG units are considered in equal rates and the discrepancy in power lines parameters must be known in advance, which reduces the accuracy of the control strategy. [22] proposes a method for reactive power sharing by changing the $V-Q$ slope and tuning corresponding droop gains. However, both of [22] and [27] need the reference reactive power which is not available in IM especially after transition from CM to IM. Besides, in transition between CM to IM, the operating point of the MG changes dramatically, especially if this happens in a fault situation. The method presented in [23] corrects the voltage droop characteristics to decrease the reactive power sharing error. However, the power quality distortion, additional power losses and complexity in implementing of control system are disadvantages of the method. The authors in [24] propose an adaptive droop controller to secure dynamic stability of power sharing in MGs. Derivative parts of $\mathrm{P}$ and $\mathrm{Q}$ are added to the conventional $f-P$ and $V-Q$ droop controls, respectively, and the corresponding gains are tuned adaptively according to output active and reactive power variations. It focuses on the stability improvement of droop controller, but reactive power sharing is not addressed properly. With investigating the complex impedance effect on the droop control performance, a virtual complex impedance is proposed in [25] to decouple active and reactive power droop controllers. It mostly deals with VSI's output impedance design, and reactive power sharing is still an issue. A virtual impedancebased method is proposed in [26] for fundamental and harmonic load sharing with voltage harmonic compensation. Although the method improves the reactive and harmonic power sharing, reactive power sharing is not implemented accurately. In [28] an improved droop control strategy is proposed to achieve accurate reactive power sharing between two identical DG units with 
asymmetrical feeders. It is based on communication link and accuracy of power sharing between unequal DG units is not clarified. A decentralized method for accurate reactive power sharing and securing dynamic stability of $V-Q$ control loop is presented in [29]. However, the reactive power reference estimation process would be less accurate in networked MGs, as DG units do not have the access to real time feeder parameters without employing high band-with communication link.

Generally, despite of the considerable efforts done in these works, presented methods are straightforward for parallel DG units but not for the multi-bus MGs (MBMGs). Besides, the simple parallel connection of DG units seems to not be very common, because of the dispersed installation of DG units in the radial distribution grids. Hence, the new group of research has been done to address the power sharing issue in networked or MBMGs [30]-[33]. These works are mostly based on consensus control system by using the low band-width communication network which is already installed in the MG to communicate between control levels, to send and receive local data to adjacent DG units. Schiffer et al. elaborate dynamic stability of consensus control for reactive power sharing in MGs with dominantly inductive power lines [30]. In [31] virtual impedance is adjusted by means of consensus control signals to establish precise reactive power sharing among parallel DG units. The feeder's impedance is considered dominantly inductive and the stability analysis is done regardless of the grid topology influence on the control system. In [32] a consensus control is adopted in the secondary level to address power sharing issues in MBMGs with dominantly inductive impedance. Only $V-Q$ control loop is considered in the small signal model, while the MG topology and $f-P$ droop loop are not inserted in the system model for stability analysis. In [33] a consensus-based droop control approach is developed to obtain accurate active and reactive power sharing in either dominantly inductive or resistive networked MG. However, the presented methods do not deal with $\mathrm{X} / \mathrm{R}$ ratio variation of the grid impedance, and the power network model is not considered in the stability analysis properly.

In this work, a novel fuzzy-based consensus algorithm is developed to achieve accurate power sharing in MBMGs. In the proposed method, fuzzy logic is adopted to model $\mathrm{X} / \mathrm{R}$ ratio of the interconnecting power lines into the consensus signals, so that, regardless of the nature of feeder impedance, DG units are properly participated in accurate power and reactive sharing. The proposed dynamic fuzzy controller adjusts consensus signal ratios considering the MG operating point and $\mathrm{X} / \mathrm{R}$ ratio of individual interconnecting lines between DG units. Therefore, the developed model is applicable to any MG with arbitrary topology and X/R ratio of grid impedance.

In order to conduct the stability analysis a novel small signal model is required by which the interaction of droop controllers as well as cross coupling effect are realized rather than taking the small signal model of only individual power converters conducted in [22]-[33]. In this regard, the authors proposed a novel small signal model in [34]. However, the accurate reactive power sharing and incorporating the corresponding controller model into the small signal model of MBMG are not addressed. In present paper, 
a novel state-space model for MBMGs is developed in which $f-P$ and $V$ - $Q$ control loops of all individual droop controllers are modeled based on their interaction through the power network. Drawing the root locus of the proposed small signal model with respect to feeders' impedance variation, shows eigenvalue movement to the unstable region after decreasing the $\mathrm{X} / \mathrm{R}$ ratio of the interconnecting power line impedance. Finally, the proposed consensus control is modeled into the proposed system model to analyze the stability and performance of the control system. In the next section, the small signal model is developed, and the fuzzyconsensus control is proposed in Section 3. Stability analysis is presented in Section 4. Then simulation results show the effectiveness of the proposed method in Section 5, and finally conclusion is drawn in Section 6.

\section{MBMG Small SigNAL MODEL}

\subsection{MBMG Structure}

The MBMG architecture is depicted in Fig. 1. Each DG unit is connected to its related bus via power converter interface. Adjacent buses are connected to each other by low voltage interconnecting power lines, in arbitrary radial or meshed topology, as well as low band-width communication links.

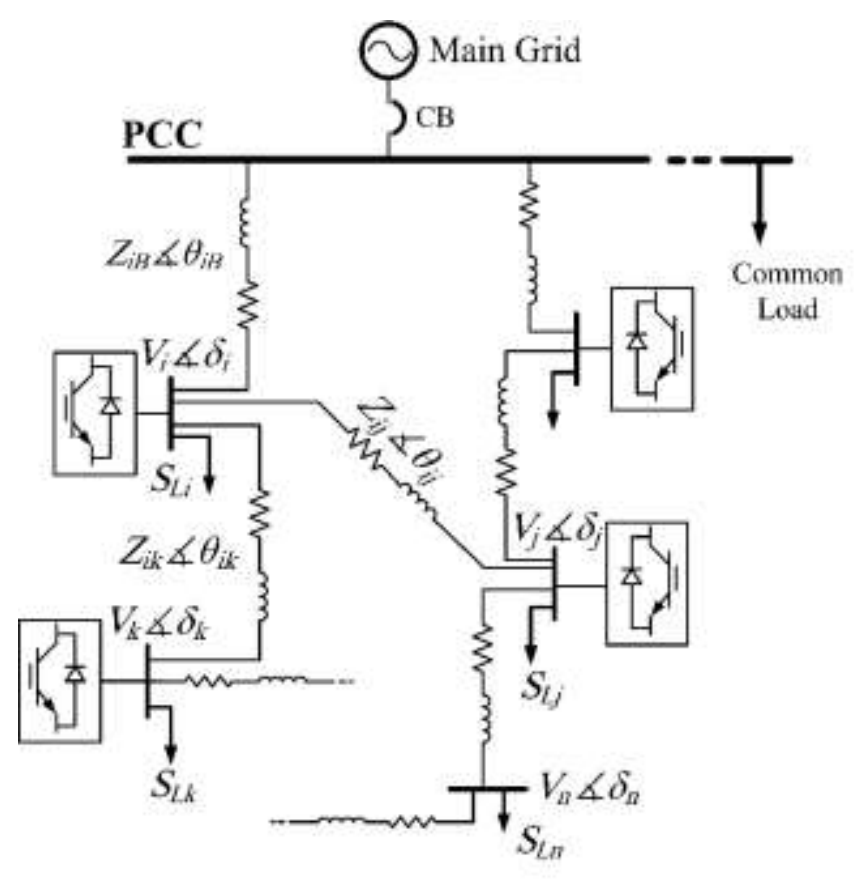

Fig. 1. MBMG topology

\subsection{Small Signal Model}

In order to develop the MBMG small signal model, first we need to obtain the power flow equations. For the power flowing from bus $i$ to bus $j$, we have: 
$\widetilde{I}_{i j}=\frac{V_{i} \angle \delta_{i}-V_{j} \angle \delta_{j}}{Z_{i j} \angle \theta_{i j}}$

$\widetilde{S}_{i j}=\widetilde{V}_{i} \cdot \widetilde{I}_{i j}^{*}=\frac{V_{i}^{2} \angle \theta_{i j}-V_{i} \cdot V_{j} \angle\left(\delta_{i}-\delta_{j}+\theta_{i j}\right)}{Z_{i j}}$

$P_{i j}=\frac{V_{i}^{2} \cdot \cos \left(\theta_{i j}\right)}{Z_{i j}}-\frac{V_{i} \cdot V_{j} \cdot \cos \left(\delta_{i}-\delta_{j}+\theta_{i j}\right)}{Z_{i j}}$

$Q_{i j}=\frac{V_{i}^{2} \cdot \sin \left(\theta_{i j}\right)}{Z_{i j}}-\frac{V_{i} \cdot V_{j} \cdot \sin \left(\delta_{i}-\delta_{j}+\theta_{i j}\right)}{Z_{i j}}$

where $\tilde{l}$ is the voltage phasor at bus $i, V_{i}$ and $\delta_{i}$ are the voltage magnitude and phase angle at bus $i$, respectively, $\tilde{I}_{i j}$, $\tilde{S}_{i j}, P_{i j}$ and $Q_{i j}$ are the current phasor, complex power, active power and reactive power flowing from bus $i$ to bus $j$, respectively. $Z_{i j}$ and $\theta_{i j}$ are the magnitude and the phase angle of the impedance of the interconnecting line between bus $i$ and $j$, respectively. By expanding the second terms of right hand sides of (3)-(4), we have:

$P_{i j}=\frac{V_{i}}{Z_{i j}}\left[\left(V_{i}-V_{j} \cdot \cos \left(\delta_{i j}\right)\right) V_{j} \cdot \sin \left(\delta_{i j}\right)\right]\left[\cos \left(\theta_{i j}\right) \sin \left(\theta_{i j}\right)\right]^{T}$

$Q_{i j}=\frac{V_{i}}{Z_{i j}}\left[-V_{j} \cdot \sin \left(\delta_{i j}\right) \quad\left(V_{i}-V_{j} \cdot \cos \left(\delta_{i j}\right)\right)\right]\left[\begin{array}{ll}\cos \left(\theta_{i j}\right) & \left.\sin \left(\theta_{i j}\right)\right]^{T}\end{array}\right.$

where $\delta_{i j}=\delta_{i}-\delta_{j}$. At each bus, the power flow equations are:

$$
\begin{aligned}
& 0=-P_{i}+\sum_{j=1}^{n} \sigma_{i j} \cdot P_{i j}+P_{L i} \\
& 0=-Q_{i}+\sum_{j=1}^{n} \sigma_{i j} \cdot Q_{i j}+Q_{L i}
\end{aligned}
$$

where $P_{i}$ and $Q_{i}$ are the generated active and reactive power, respectively, $\sigma_{i j}$ is the entry of adjacency matrix which is 1 if the $i^{t h}$ bus is connected to $j^{\text {th }}$ bus and 0 if they are not connected buses. To control the output active and reactive power of DG units in the autonomous MGs, by employing conventional $f-P$ and $V-Q$ droop control at VSIs, we have:

$$
\begin{aligned}
& \omega_{i}=\omega_{0}-k_{p i} \bar{P}_{i} \\
& V_{i, r e f}=V_{0}-k_{q i} \int \bar{Q}_{i} d t
\end{aligned}
$$

where $\omega_{i} \& V_{i, r e f}\left(\omega_{0} \& V_{0}\right)$ are the operating (nominal) angular frequency and voltage magnitude, respectively, $k_{p i} \& k_{q i}$ are the $f$ $P$ and $V$ - $Q$ droop coefficients respectively, $\bar{P}_{i}$ and $\bar{Q}_{i}$ are the output average active and reactive powers of DG units, respectively, which are given by passing instantaneous active and reactive power through the low pass filter. In order to define state variables of the MBMG, we have: 
$\dot{\delta}_{i}=\omega_{i}-\omega_{0}$

The V-SQ.dt droop control is adopted to improve reactive power sharing among DG units. So Substituting (9) into (11) and employing $V$ - $\int Q . d t$ droop control for islanded operation of MBMG we have:

$\begin{array}{llrl}\omega_{i}=\omega_{0}-k_{p i} \bar{P}_{i} & \text { or } & & \dot{\Delta \delta_{i}}=-k_{p_{i}} \cdot \Delta \bar{P}_{i} \\ V_{i, r e f}=V_{0}-\int k_{q i} \cdot \bar{Q}_{i} d t & \text { or } & \dot{\Delta V}_{i}=-k_{q i} \cdot \Delta \bar{Q}_{i}\end{array}$

The VSI's inner control loops (voltage and current) track the reference values with fast response in comparison to droop control. Therefore, their dynamics are ignored here. The other component which influences the dynamics of MG system is the low-pass filter which is used to achieve the average values of active and reactive power. In order to embed the first order filter, with the transfer function of $\omega_{c} /\left(s+\omega_{c}\right)$ in the system model, from (12) and (13) we have:

$$
\begin{aligned}
\Delta \ddot{\delta}_{i} & =-\omega_{c} \cdot \dot{\Delta}_{i}-\omega_{c} \cdot k_{p i} \cdot \Delta P_{i} \\
\Delta \ddot{V}_{i} & =-\omega_{c} \cdot \Delta \dot{V}_{i}-\omega_{c} \cdot k_{q i} \cdot \bar{Q}_{i}
\end{aligned}
$$

Now we define the state variables as:

$$
\begin{aligned}
& \text { for } i=1: n \\
& x_{i 1}=\Delta \dot{\delta}_{i}, \quad x_{i 2}=\Delta \partial_{i}, \quad x_{i 3}=\Delta \dot{V}_{i}, \quad x_{i 4}=\Delta v_{i}
\end{aligned}
$$

where $n$ is the number of MBMG buses. From (7)-(8) and (14)-(16), the small signal mathematical model of MBMG is obtained as:

$$
\begin{aligned}
& \text { for } i=1: n \\
& \dot{x}_{i 1}=-\omega_{c} \cdot x_{i 1}-\omega_{c} \cdot k_{p i} \sum_{j=1}^{n} \sigma_{i j} \cdot \Delta P_{i j}-\omega_{c} \cdot k_{p i} \Delta P_{L i} \\
& \dot{x}_{i 2}=x_{i 1} \\
& \dot{x}_{i 3}=-\omega_{c} \cdot x_{i 3}-\omega_{c} \cdot k_{q i} \cdot \sum_{j=1}^{n} \sigma_{i j} \cdot \Delta Q_{i j}-\omega_{c} \cdot k_{q i} \Delta Q_{L i} \\
& \dot{x}_{i 4}=x_{i 3}
\end{aligned}
$$

where index $i$ denotes the $i^{\text {th }} \mathrm{DG}$ unit, and $\Delta P_{i j} \& \Delta Q_{i j}$ denote the flowing active and reactive power variation from bus $i$ to bus $j$, $\Delta P_{L i} \& \Delta Q_{L i}$ are the active and reactive load variation of the $i^{\text {th }}$ bus, which are considered as a disturbance to the system. To get the Jacobian matrix, by linearizing of (5) and (6), we have: 


$$
\begin{aligned}
& \Delta P_{i j}=\left[2 \cdot \alpha_{i j} \cdot V_{i o}-\alpha_{i j} \cdot V_{j 0} \cdot \cos \left(\delta_{i j 0}\right)+\beta_{i j} \cdot V_{j 0} \cdot \sin \left(\delta_{i j 0}\right)\right] \Delta V_{i}+\left[\alpha_{i j} \cdot V_{i 0} \cdot V_{j 0} \cdot \sin \left(\delta_{i j 0}\right)+\beta_{i j} \cdot V_{i 0} \cdot V_{j 0} \cdot \cos \left(\delta_{i j 0}\right)\right] \Delta \delta_{i} \\
& +\left[\beta_{i j} \cdot V_{i 0} \cdot \sin \left(\delta_{i j 0}\right)-\alpha_{i j} \cdot V_{i 0} \cdot \cos \left(\delta_{i j 0}\right)\right] \Delta V_{j}-\left[\alpha_{i j} \cdot V_{i 0} \cdot V_{j 0} \cdot \sin \left(\delta_{i j 0}\right)+\beta_{i j} \cdot V_{i 0} \cdot V_{j 0} \cdot \cos \left(\delta_{i j 0}\right)\right] \Delta \delta_{j} \\
& \Delta Q_{i j}=\left[2 \cdot \beta_{i j} \cdot V_{i o}-\beta_{i j} \cdot V_{j 0} \cdot \cos \left(\delta_{i j 0}\right)-\alpha_{i j} \cdot V_{j 0} \cdot \sin \left(\delta_{i j 0}\right)\right\rfloor \Delta V_{i}-\left\lfloor\alpha_{i j} \cdot V_{i 0} \cdot V_{j 0} \cdot \cos \left(\delta_{i j 0}\right)-\beta_{i j} \cdot V_{i 0} \cdot V_{j 0} \cdot \sin \left(\delta_{i j 0}\right)\right\rfloor \Delta \delta_{i} \\
& -\left[\beta_{i j} \cdot V_{i 0} \cdot \cos \left(\delta_{i j 0}\right)+\alpha_{i j} \cdot V_{i 0} \cdot \sin \left(\delta_{i j 0}\right)\right] \Delta V_{j}+\left[\alpha_{i j} \cdot V_{i 0} \cdot V_{j 0} \cdot \cos \left(\delta_{i j 0}\right)-\beta_{i j} \cdot V_{i 0} \cdot V_{j 0} \cdot \sin \left(\delta_{i j 0}\right)\right] \Delta \delta_{j}
\end{aligned}
$$

where $\alpha_{i j}=\cos \left(\theta_{i j}\right) / Z_{i j} \& \beta_{i j}=\sin \left(\theta_{i j}\right) / Z_{i j}$, and the zero index denotes the values at the nominal operating point, which are achieved by running power flow study. Finally, the overall state space model of MBMG is achieved by (23):

$$
x_{i}=\left(J_{i i} \cdot x_{i}+\sum_{j=1}^{n} J_{i j} \cdot x_{j}\right)+\left(\omega_{c} \cdot K_{i}\right) \cdot d_{i}
$$

where $J_{i i}$ and $J_{i j}$ are defined in (24)-(25), respectively.

$J_{i i}=-\omega_{c}\left[\begin{array}{cccc}1 & k_{p i} \sum_{j=1}^{n} \sigma_{i j} \frac{\partial P_{i j}}{\partial \delta_{i}} & 0 & k_{p i} \sum_{j=1}^{n} \sigma_{i j} \frac{\partial P_{i j}}{\partial V_{i}} \\ \frac{-1}{\omega_{c}} & 0 & 0 & 0 \\ 0 & k_{q i} \sum_{j=1}^{n} \sigma_{i j} \frac{\partial Q_{i j}}{\partial \delta_{i}} & 1 & k_{q i} \sum_{j=1}^{n} \sigma_{i j} \frac{\partial Q_{i j}}{\partial V_{i}} \\ 0 & 0 & \frac{-1}{\omega_{c}} & 0\end{array}\right]$

$J_{i j}=-\sigma_{i j} \omega_{c}\left[\begin{array}{cccc}0 & k_{p i} \frac{\partial P_{i j}}{\partial \delta_{j}} & 0 & k_{p i} \frac{\partial P_{i j}}{\partial V_{j}} \\ 0 & 0 & 0 & 0 \\ 0 & k_{q i} \frac{\partial Q_{i j}}{\partial \delta_{j}} & 0 & k_{q i} \frac{\partial Q_{i j}}{\partial V_{j}} \\ 0 & 0 & 0 & 0\end{array}\right]$

$K_{i}=\left[\begin{array}{cccc}-k_{p i} & 0 & 0 & 0 \\ 0 & 0 & -k_{q i} & 0\end{array}\right]^{T}, \quad d_{i}=\left[\begin{array}{ll}\Delta P_{L i} & \Delta Q_{L i}\end{array}\right]^{T}$

The block diagram of the MBMG system is shown in Fig. 2, where the double line arrows denote vector quantities. The related block diagram consists of two control loops, $\delta-\int P . d t$ and $V-\int Q . d t$, which are coupled by the Jacobian matrix $J_{i j}$ (the linearized form of power flow equation in the power network). 


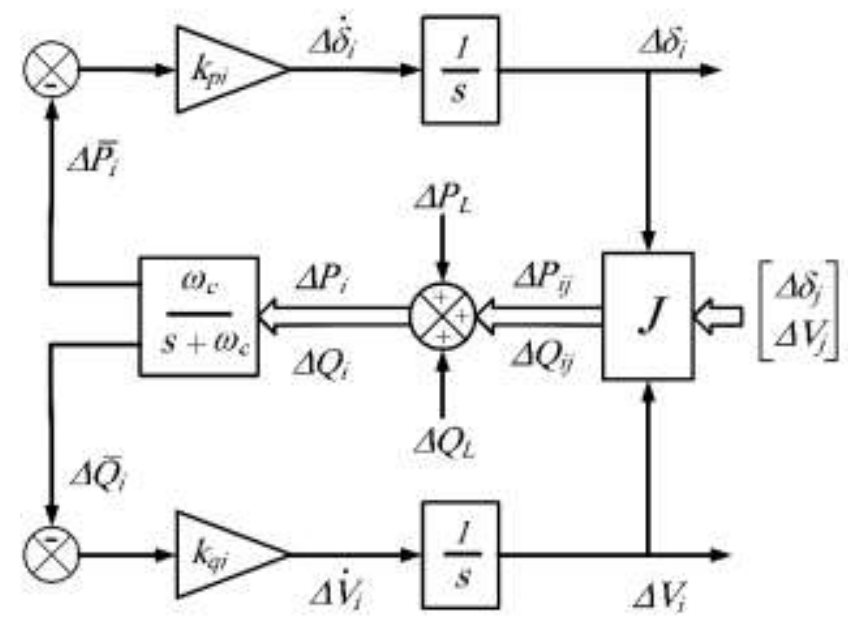

Fig. 2. Block diagram of droop-based control system for islanded MG.

The eigenvalue loci of the droop-based control system in MBMGs with respect to decreasing X/R ratio of the grid is depicted in Fig. 3. A comparison is made between the developed Power Network (PN-based) model in this paper and the conventional Parallelbased (P-based) model [24]. In conventional P-based models, the overall small signal model of MG is obtained by transferring the small signal model of each VSI to a given reference frame. The transformed variable is usually the $d$ - $q$ components of the VSI output current which flows through the interconnecting power line. By contrast, in the proposed PN-based model, power flow equations are used to model the interaction of $\delta-\int P d t$ and $V-\int Q d t$ controllers at individual DG buses via the power network (considering that the state variables are voltage magnitude and phase angle). The PN-based model reveals unstable regions which the conventional parallel based model does not show.

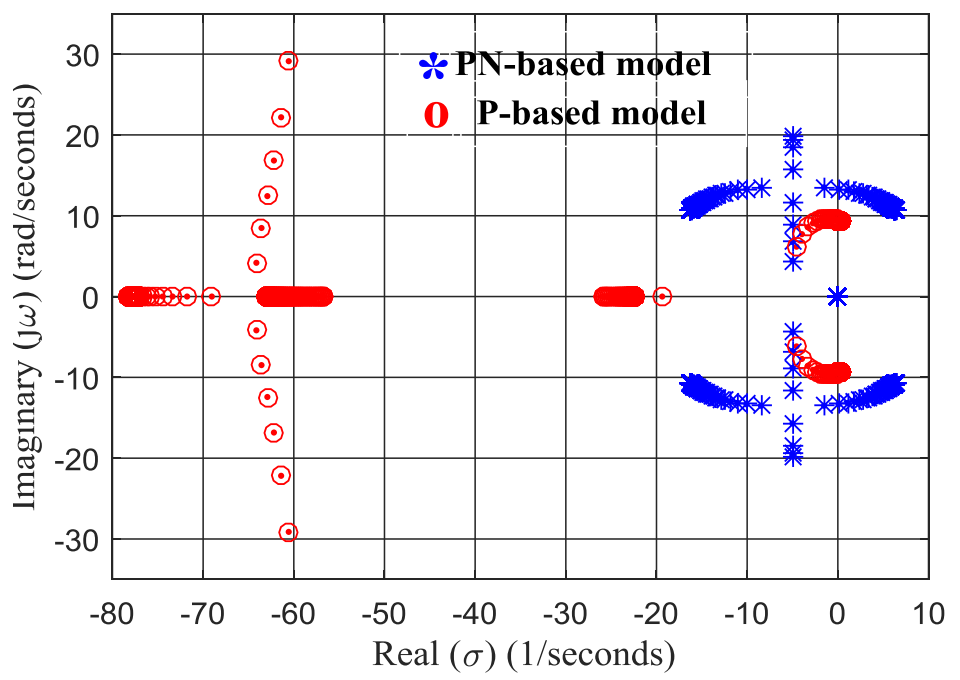

Fig. 3. Root locus of the Power network-based (PN-based) MBMG's small signal model with respect to decreasing the grid inductance (and X/R ratio).

\section{MBMG CONTROL SYSTEM}


The insufficiency of droop control is the essential challenge of accurate power sharing in MBMGs which should be dealt with. According to Fig. 2, the conventional $f-P$ and $V-Q$ control loops are decoupled loops if they are separated in the Jacobian matrix. The grid impedance should be dominantly inductive or resistive to decouple P and Q control, which is not feasible in MGs. So, the low $\mathrm{X} / \mathrm{R}$ ratio of grid impedance is a restriction on decoupling the conventional $f-P$ and $v-Q$ droop control loops in $\mathrm{MGs}$. Moreover, the voltage drop along the interconnecting power line (feeder) causes the reactive power sharing inaccurate. In this paper, fuzzy consensus control is adopted to overcome the MG control disadvantage in precise power sharing.

\subsection{Consensus Control}

The low band-width communication network is required in MGs to send and collect data, $P, Q, f$ and $V$ reference values, to DG units, especially in the tertiary and secondary levels for energy management and power quality improvement purposes. So, it can be benefited in the primary level to improve droop control performance. The consensus signals are considered as input signals to the controller system as:

$\dot{\gamma}_{i}=-k_{c o n s, i} \cdot \sum_{j=1}^{n} \sigma_{i j}\left(\psi_{i}-\psi_{j}\right)$

where $\gamma$ is the consensus signal, $k_{c o n s}$ is the consensus control gain, and $\Psi_{i}$ and $\Psi_{j}$ are the relevant variable of $i^{\text {th }}$ and $j^{\text {th }}$ adjacent units which should reach consensus.

\subsection{Consensus signals in MG}

DG units in MGs are usually of small scale capacity. To prevent DGs from being overloaded, or even MGs from being collapsed, power sharing is implemented among DG units in MG proportional to their capacity, according to (28)-(29) [2], [35].

$k_{p_{1}} \cdot P_{1}=k_{p_{2}} \cdot P_{2}=\ldots=k_{p_{i}} P_{i}=\ldots=k_{p n} P_{n}$

$k_{q 1} \cdot Q_{1}=k_{q 2} \cdot Q_{2}=\ldots=k_{q i} Q_{i}=\ldots=k_{q n} Q_{n}$

Consensus control is adopted to modify droop controller signals in (12)-(13) to reach precise power sharing as:

$$
\begin{aligned}
& \omega_{i}=\omega_{0}-k_{p i} \bar{P}_{i}-k_{c o n s, p i} \cdot \gamma_{p i} \\
& V_{i, r e f}=V_{0}-\int k_{q i} \bar{Q}_{i} d t-k_{c o n s, q i} \cdot \gamma_{q i}
\end{aligned}
$$

where $\gamma_{p i}$ and $\gamma_{q i}$ are consensus control signals and $k_{c o n s, p i}$ and $k_{c o n s, q i}$ are the related gains for improving power sharing which are adjusted so that the desire control performance is achieved. In order to achieve power sharing target in (28)-(29), the consensusbased signals are defined as: 


$$
\begin{gathered}
\dot{\bar{\gamma}}_{p i}=\sum_{j=1}^{n} \varphi_{11 i j} \sigma_{i j}\left(k_{p i} \cdot \bar{P}_{i}-k_{p j} \cdot \bar{P}_{j}\right)-\sum_{j=1}^{n} \varphi_{12 i j} \sigma_{i j}\left(k_{q i} \cdot \bar{Q}_{i}-k_{q j} \cdot \bar{Q}_{j}\right) \\
\dot{\bar{\gamma}}_{q i}=\sum_{j=1}^{n} \varphi_{21 i j} \sigma_{i j}\left(k_{p i} \cdot \bar{P}_{i}-k_{p j} \cdot \bar{P}_{j}\right)+\sum_{j=1}^{n} \varphi_{22 i j} \sigma_{i j}\left(k_{q i} \cdot \bar{Q}_{i}-k_{q j} \cdot \bar{Q}_{j}\right)
\end{gathered}
$$

where index $i$ is the $i^{\text {th }}$ DG unit, $n$ is the number of the DG units, $k_{p i}$ and $k_{q i}$ are droop coefficients and $P_{i} \& Q_{i}$ are output power of $i^{\text {th }}$ DG unit, $\varphi_{11 i j}, \varphi_{12 i j}, \varphi_{2 l i j}$, $\varphi_{22 i j}$ are fuzzy set coefficients which are inserted into the consensus signal to model the $R / X$ ratio of power lines effects in power sharing.

\subsection{Fuzzy Consensus Coefficients}

In the MGs with small feeder impedance and low power capacity, the $\Delta \delta$ of adjacent buses is small. So, from (5)-(6) we obtain:

$$
\left[\begin{array}{c}
\Delta P_{i j} \\
\Delta Q_{i j}
\end{array}\right] \approx V_{i}\left[\begin{array}{cc}
\Delta V_{i j} & V_{j} \Delta \delta_{i j} \\
-V_{j} \Delta \delta_{i j} & \Delta V_{i j}
\end{array}\right]\left[\begin{array}{c}
\cos \left(\theta_{i j}\right) \\
\sin \left(\theta_{i j}\right)
\end{array}\right]
$$

According to (34), and noting that the frequency variation dynamically controls the phase angle, we have:

if $X / R \gg>1: \sin \left(\theta_{i j}\right) \approx 1 \& \cos \left(\theta_{i j}\right) \approx 0 \rightarrow P \propto f \quad \& \quad Q \propto V$

if $X / R<<1: \sin \left(\theta_{i j}\right) \approx 0 \& \cos \left(\theta_{i j}\right) \approx 1 \rightarrow P \propto V \quad \& \quad Q \propto-f$

The above two rules represent a Boolean $0 \& 1$ logic which is not applicable in MGs, as the $X / R$ ratio of the grid normally changes around 1 (none of $X / R>>1 \& X / R<<1$ is true). Hence, both the active power and reactive power in MGs are dependent on both the voltage magnitude and frequency, as represented in (30)-(33). Nevertheless, the $X / R$ ratio of the interconnecting line impedance determines to what extent the active power and reactive power are controlled by the voltage magnitude and frequency. To this end, fuzzy logic is proposed to adjust control gains, $\varphi_{11}, \varphi_{12}, \varphi_{21}, \varphi_{22}$ in (32)-(33), according to the $X / R$ ratio of power line impedances.

\subsubsection{Fuzzy Controller}

The Fuzzy Interface System (FIS), illustrated in Fig. 4 (a), consists of the following parts:

a) Inputs (Fuzzification): As the fuzzy logic acts based on the "degree of truth" rather than the common 1 or 0 Boolean logic, the input signals are normalized between 0 and 1 . The regulated (per unit) inputs of the fuzzy controller are defined as:

1) $\operatorname{Sin}\left(\theta_{i j}\right) ; \theta_{i j}$ is the phase angle of the $i j^{\text {th }}$ interconnecting power line. This input reflects the $X / R$ ratio of the feeder into the consensus controller. $\sin (\theta)$ is used for normalization and to better reflect its effects according to (34).

2) $\quad\left(k_{p i} . P_{i}-k_{p j} . P_{j}\right) /\left|\omega_{0}-\omega_{\min }\right|$; the error in power sharing $\left(\Delta P_{\text {error }}\right)$ is divided by the permitted band of the angular frequency variation $\left(\Delta \omega_{\text {tolerable }}\right)$. It is worth noting that in the conventional $f-P$ droop loop, $k_{p i}$ is selected so that $k_{p i} P_{n i}=\left|\omega_{0}-\omega_{\text {min }}\right|$, 
where $P_{n i}$ is the nominal power of DG $i$ and $\omega_{\min }$ is the minimum tolerable angular frequency. This input is named $\Delta \mathrm{P}_{\text {error }} / \Delta \omega_{\text {tolerable }}$ in the FIS.

3) $\left(k_{q i} Q_{i}-k_{q j} \cdot Q_{j}\right) /\left|V_{0}-V_{\min }\right|$; the error in reactive power sharing $\left(\Delta Q_{e r r o r}\right)$ is divided by the permitted band of the voltage magnitude variation $\left(\Delta V_{\text {tolerable }}\right)$. It is worth noting that in the conventional $V-Q$ droop loop, $k_{q i}$ is selected so that $k_{q i} Q_{n i}=\left|V_{0}-V_{\min }\right|$, where $Q_{n i}$ is the nominal value of reactive power delivered by DG $i$ and $V_{\min }$ is the minimum tolerable voltage magnitude. This input is named $\Delta Q_{\text {error }} / \Delta V_{\text {tolerable }}$ in the FIS.

b) Outputs: The outputs of the Fuzzy Interface System (FIS) are consensus signal coefficients: $\varphi_{11}, \varphi_{12}, \varphi_{21}, \varphi_{22}$.

c) Membership function (MF): relevant fuzzy membership functions need to be developed to reflect the effectiveness and importance of the normalized input signals to the fuzzy rules and fuzzy rules to the normalized outputs. In the developed FIS for the fuzzy-based consensus control, the Gaussian curve membership function (gaussmf) is adopted to achieve smoothness and concise notation. The Generalized bell-shaped membership function (gbellmf) is also used in the FIS. The gbellmf has more flexibility than gaussmf to approach non-fuzzy values, e.g. values of input 1 which are closed to 0 or 1; see Fig. 4(b).

d) Fuzzy rules: In order to design the proposed fuzzy controller, it is important to define proper if and then rules which are applied to the input signals. According to the input value, a fuzzy term is assigned to the input. The abbreviations of assigned fuzzy terms are: Extremely Small (ES), Very Small (VS), Small (S), Medium (M), Large (L), Very Large (VL), and Extremely Large (EL). On the other hand, these fuzzy terms are assigned to outputs' membership functions. Then fuzzy rules map the input fuzzy terms to the output fuzzy terms so that the control targets are validated. The first input is constant input to the fuzzy controller, and the second and third inputs are dynamic inputs inserted to the fuzzy controller. So, we should design a dynamic fuzzy controller to tune consensus coefficients dynamically by defining suitable fuzzy rules. The deduction which leads to defining fuzzy rules are presented as:

1) Input 1 determines the dependency of $\Delta P_{i j}$ and $\Delta Q_{i j}$ on $\Delta \delta_{i j}$ and $\Delta V_{i j}$. So for each value (fuzzy term) of input 1 , fuzzy rules select an appropriate value (fuzzy term) from individual outputs based on (34).

2) Input 2 reveals the amount of inaccuracy in active power sharing. So the value of relevant fuzzy gains is designed to get the desirable dynamic performance, the larger inaccuracy, and the larger fuzzy gains.

3) Input 3 reveals the amount of inaccuracy in reactive power sharing. This input is important from two aspects: 1) the corresponding fuzzy gains are selected to get desirable dynamic performance; 2) in contrast to active power sharing, reactive power sharing is not implemented well, initially by $V-Q$ droop control, because of voltage drop along the feeder and feeder impedance mismatch which are dependent on the MBMG structure. Hence $\left(k_{q i} \cdot Q_{i}-k_{q j} \cdot Q_{j}\right)$, which is inserted 
into (32), might be large and cause the frequency going beyond the permitted limit. So the output $\varphi_{12}$ should be smaller for large values of input 3 .

The FIS diagram and output surface for second output $\left(\varphi_{12}\right)$ are depicted in Fig. 4, and the fuzzy rule table for "Mamdani" FIS is given in Table I.

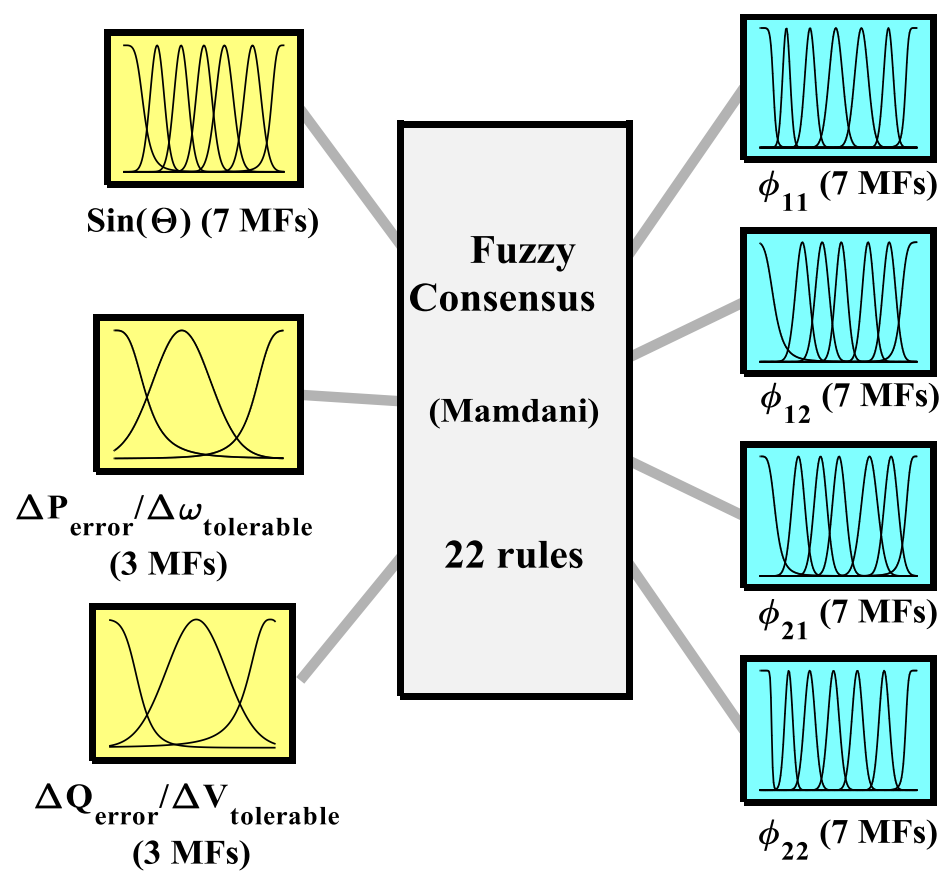

(a)

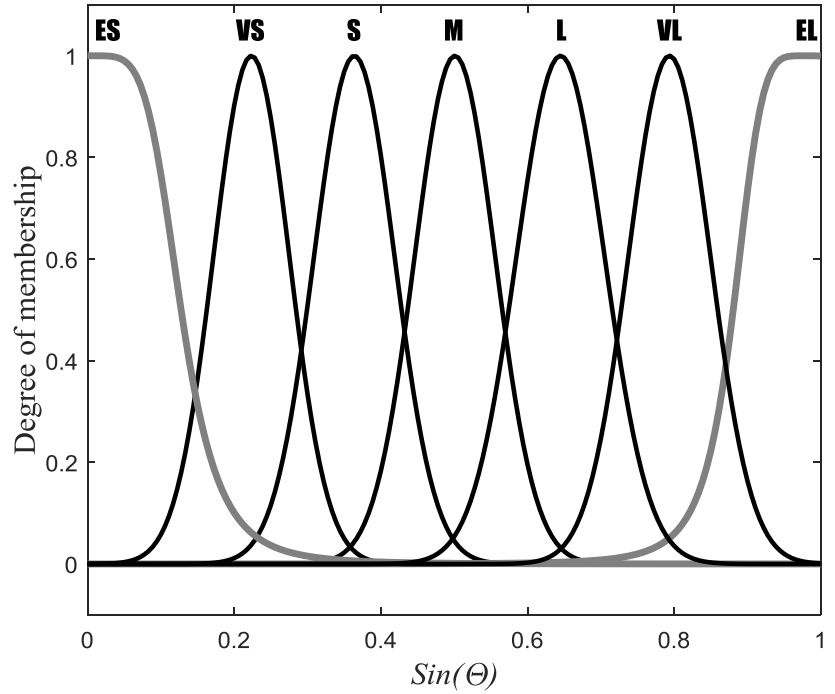

(b) 


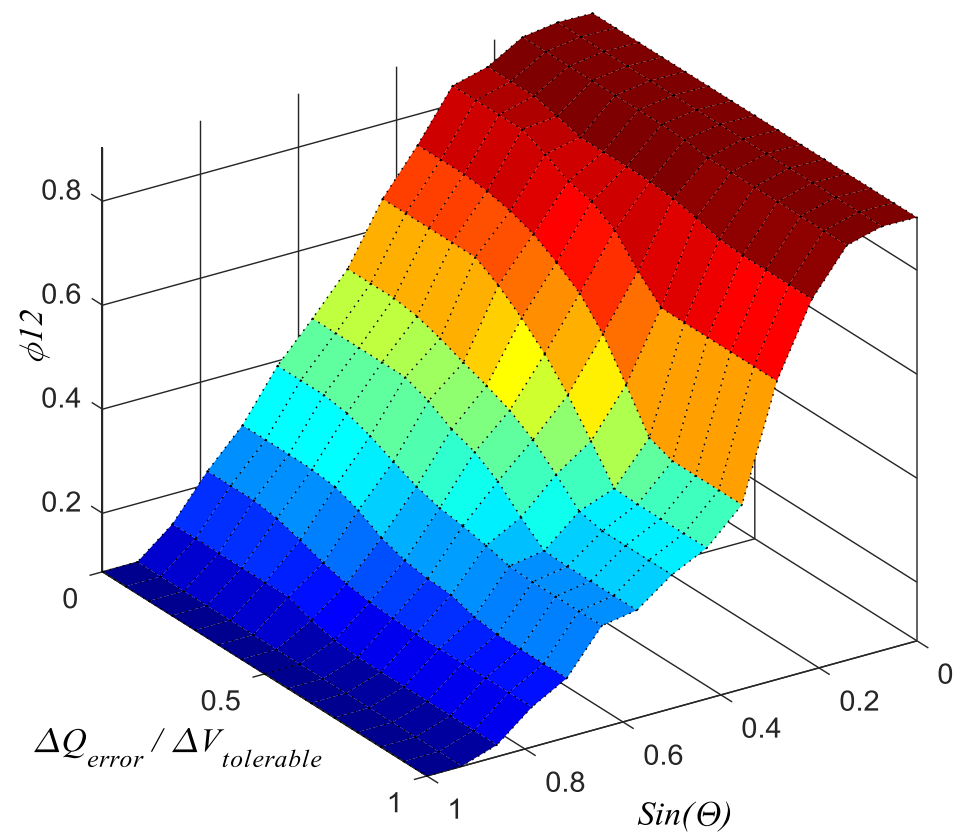

(c)

Fig. 4. FIS for the consensus control, (a) FIS diagram including 3 inputs and 4 outputs (b) Membership function for input 1. The ES and EL terms are represented by gbellmf and other values are represented by gaussmf, (c) Output surface for output $2\left(\varphi_{12}\right)$

TABLE I: FUZZY RULES

\begin{tabular}{|c|c|c|c|c|c|c|c|c|c|c|c|c|c|c|c|c|c|c|c|c|c|c|}
\hline Input1 & EL & $\mathrm{VL}$ & $\mathrm{VL}$ & $\mathrm{VL}$ & $\mathrm{VL}$ & $\mathrm{L}$ & L & L & $\mathrm{L}$ & M & $\mathrm{M}$ & M & M & $\mathrm{S}$ & $\mathrm{S}$ & $\mathrm{S}$ & $\mathrm{S}$ & VS & VS & VS & VS & ES \\
\hline Input2 & - & - & $\mathrm{S}$ & M & L & - & $\mathrm{S}$ & M & $\mathrm{L}$ & - & $\mathrm{S}$ & M & $\mathrm{L}$ & - & $\mathrm{S}$ & M & $\mathrm{L}$ & - & $\mathrm{S}$ & M & L & - \\
\hline Input3 & - & - & $\mathrm{S}$ & $\mathrm{M}$ & $\mathrm{L}$ & - & $\mathrm{S}$ & $\mathrm{M}$ & $\mathrm{L}$ & - & $\mathrm{S}$ & $\mathrm{M}$ & $\mathrm{L}$ & - & $\mathrm{S}$ & $\mathrm{M}$ & $\mathrm{L}$ & - & $\mathrm{S}$ & $\mathrm{M}$ & $\mathrm{L}$ & - \\
\hline$\Phi_{11}$ & EL & $\mathrm{VL}$ & $\mathrm{VL}$ & $\mathrm{VL}$ & $\mathrm{VL}$ & $\mathrm{L}$ & $\mathrm{L}$ & $\mathrm{L}$ & $\mathrm{L}$ & $\mathrm{M}$ & $\mathrm{M}$ & $\mathrm{M}$ & $\mathrm{M}$ & $\mathrm{S}$ & $\mathrm{S}$ & $\mathrm{S}$ & $\mathrm{S}$ & $\mathrm{VS}$ & $\mathrm{VS}$ & $\mathrm{VS}$ & VS & ES \\
\hline$\Phi_{12}$ & ES & VS & $\mathrm{S}$ & VS & ES & $\mathrm{S}$ & $\mathrm{M}$ & $\mathrm{S}$ & VS & $\mathrm{M}$ & $\mathrm{L}$ & $\mathrm{M}$ & $\mathrm{S}$ & $\mathrm{L}$ & VL & $\mathrm{L}$ & $\mathrm{M}$ & VL & EL & VL & $\mathrm{L}$ & EL \\
\hline$\Phi_{21}$ & ES & VS & EL & VL & $\mathrm{L}$ & $\mathrm{S}$ & VL & $\mathrm{L}$ & $\mathrm{M}$ & $\mathrm{M}$ & $\mathrm{L}$ & $M$ & $\mathrm{~S}$ & $\mathrm{~L}$ & $\mathrm{M}$ & $\mathrm{S}$ & VS & VL & $\mathrm{S}$ & VS & ES & EL \\
\hline$\Phi_{22}$ & EL & VL & $\mathrm{VL}$ & $\mathrm{VL}$ & $\mathrm{VL}$ & $\mathrm{L}$ & $\mathrm{L}$ & $\mathrm{L}$ & $\mathrm{L}$ & $\mathrm{M}$ & $\mathrm{M}$ & $\mathrm{M}$ & $\mathrm{M}$ & $\mathrm{S}$ & $\mathrm{S}$ & $\mathrm{S}$ & $\mathrm{S}$ & $\mathrm{VS}$ & VS & VS & VS & ES \\
\hline
\end{tabular}

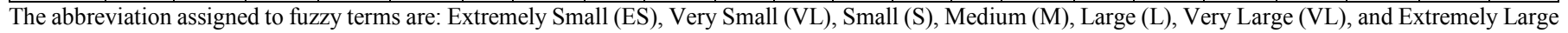
(EL).

\section{Stability ANALYSIS}

In Section 2, the small signal model of MBMG is developed considering the interaction of droop controllers at DG units via the power network. The consensus control should be inserted to the model to assess the stability of the control system. From (30) and (31) we have:

$\Delta \dot{\delta}_{i}=-k_{p_{i}} \Delta \bar{P}_{i}-k_{c o n s, p i} \Delta \bar{\gamma}_{p i}$
$\Delta \dot{V}_{i}=V_{0}-k_{q i} \Delta \bar{Q}_{i}-k_{c o n s, q i} \Delta \bar{\gamma}_{q i}$

After modeling low pass filter transfer function $\left(\omega_{c} /\left(s+\omega_{c}\right)\right)$ in $(35)-(36)$, for $i^{\text {th }} \mathrm{DG}$ unit we have:

$$
\begin{aligned}
& \Delta \ddot{\partial}_{i}=-\omega_{c} \Delta \dot{\delta}_{i}-\omega_{c} k_{p_{i}} \sum_{j=1}^{n} \sigma_{i j} \Delta P_{i j}-\omega_{c} k_{c o n s, p i} \Delta \gamma_{p i} \\
& \Delta \ddot{V}_{i}=-\omega_{c} \Delta \dot{V}_{i}-\omega_{c} k_{q i} \sum_{j=1}^{n} \sigma_{i j} \Delta Q_{i j}-\omega_{c} k_{c o n s, q i} \Delta \gamma_{q i}
\end{aligned}
$$


We define new state variables as:

for $i=1: n$

$x_{c i}=\left[\begin{array}{cccccc}\Delta \dot{\delta}_{i} & \Delta \delta_{i} & \Delta \dot{V}_{i} & \Delta V_{i} & \Delta \gamma_{p i} & \Delta \gamma_{q i}\end{array}\right]^{T}$

With the same process similar to (16)-(23) the state-space model of the consensus-based droop controller is obtained. The dominant eigenvalue loci of the consensus-based droop control is depicted in Fig. 5. The movement direction are aligned with increasing the consensus gains. While some modes are improved with adopting consensus signals and increasing relevant gains, some other modes are moving toward unstable region, which must be considered in selecting control parameters. Nevertheless, as it is investigated in the simulation results and in the discussion section, the proposed fuzzy consensus control provides both desirable dynamic performance as well as dynamic stability.

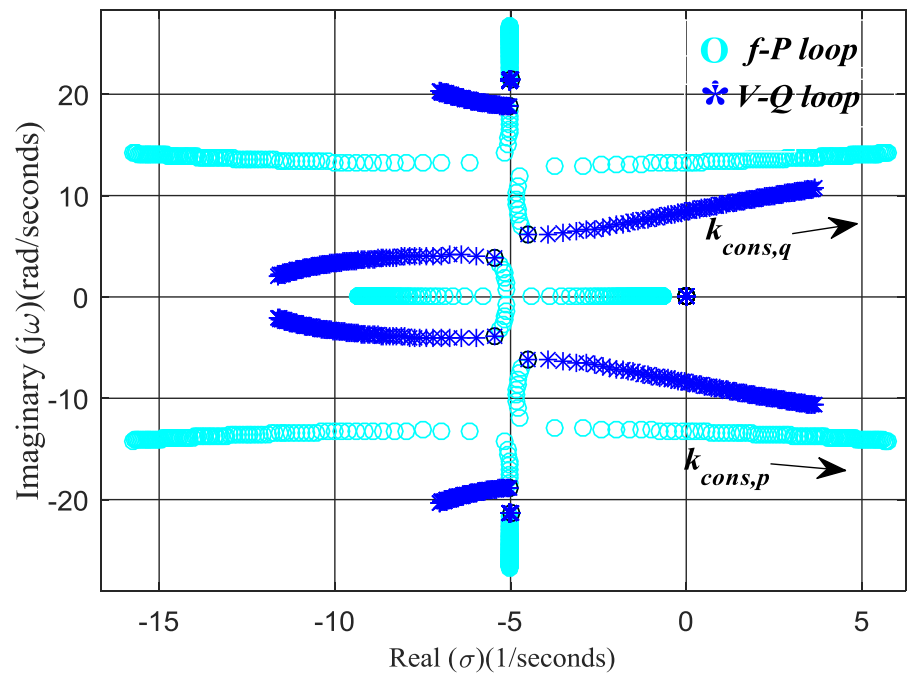

Fig. 5. Dominant eigenvalue loci of the consensus-based droop control system in respect to consensus gains variations, the movement direction is toward increasing the corresponding consensus gains.

\section{Simulation Results}

The MBMG given in Fig. 6 is simulated in the MATLAB/Simulink on a high-performance Linux cluster to evaluate the effectiveness of the proposed fuzzy-consensus control method. The data related to the DG units and feeders' impedance at each case is given in Table II, where the $\mathrm{X} / \mathrm{R}$ ratio as well as the contribution of DG units in power sharing are considered different to assess the performance of the proposed method. The disconnector switch $\mathrm{S}_{12}$ is embedded into the MG's power network for topology maneuver purposes as the meshed topology improves reliability of the system. 
TABLE II: MBMG DATA

\begin{tabular}{|c|c|c|c|c|c|}
\hline \multirow{6}{*}{$\begin{array}{c}\text { Case } 1 \\
X / R \approx 4 \\
S_{12}: \text { open }\end{array}$} & \multicolumn{2}{|c|}{ DG units } & DG 1 & DG 2 & DG 3 \\
\hline & \multicolumn{2}{|c|}{$\mathrm{k}_{\mathrm{p}}$} & $1 \mathrm{e}-5$ & $1 \mathrm{e}-5$ & $1 e-5$ \\
\hline & \multicolumn{2}{|c|}{$\mathrm{k}_{\mathrm{q}}$} & $0.5 \mathrm{e}-3$ & $0.5 \mathrm{e}-3$ & $0.5 \mathrm{e}-3$ \\
\hline & Grid & Line 12 & Line 13 & Line 24 & Line 34 \\
\hline & Resistance $(\Omega)$ & - & 0.04 & 0.052 & 0.028 \\
\hline & Inductance $(\mathrm{H})$ & - & $5 e-4$ & $6.5 \mathrm{e}-4$ & $3.5 \mathrm{e}-4$ \\
\hline \multirow{6}{*}{$\begin{array}{c}\text { Case 2 } \\
X / R \approx 1 \\
S_{12}: \text { open }\end{array}$} & \multicolumn{2}{|c|}{ DG units } & DG 1 & DG 2 & DG 3 \\
\hline & \multicolumn{2}{|c|}{$\mathrm{k}_{\mathrm{p}}$} & $0.5 \mathrm{e}-5$ & $1 \mathrm{e}-5$ & $1 \mathrm{e}-5$ \\
\hline & \multicolumn{2}{|c|}{$\mathrm{k}_{\mathrm{q}}$} & $0.25 \mathrm{e}-3$ & $0.5 \mathrm{e}-3$ & $0.5 \mathrm{e}-3$ \\
\hline & Grid & Line 12 & Line 13 & Line 24 & Line 34 \\
\hline & $\operatorname{Resistance}(\Omega)$ & - & 0.08 & 0.072 & 0.096 \\
\hline & Inductance $(\mathrm{H})$ & - & $2.5 \mathrm{e}-4$ & $2.25 \mathrm{e}-4$ & $3 e-4$ \\
\hline \multirow{6}{*}{$\begin{array}{c}\text { Case } 3 \\
X / R \approx 2 \\
S_{12}: \text { closed }\end{array}$} & \multicolumn{2}{|c|}{ DG units } & DG 1 & DG 2 & $\overline{\text { DG } 3}$ \\
\hline & \multicolumn{2}{|c|}{$\mathrm{k}_{\mathrm{p}}$} & $0.5 \mathrm{e}-5$ & $1 \mathrm{e}-5$ & $1 \mathrm{e}-5$ \\
\hline & \multicolumn{2}{|c|}{$\mathrm{k}_{\mathrm{q}}$} & $0.25 \mathrm{e}-3$ & $0.5 \mathrm{e}-3$ & $0.5 \mathrm{e}-3$ \\
\hline & Grid & Line 12 & Line 13 & Line 24 & Line 34 \\
\hline & Resistance $(\Omega)$ & 0.043 & 0.048 & 0.063 & 0.0336 \\
\hline & Inductance $(\mathrm{H})$ & $2.25 \mathrm{e}-4$ & $2.5 \mathrm{e}-4$ & $2.25 \mathrm{e}-4$ & $3 e-4$ \\
\hline
\end{tabular}

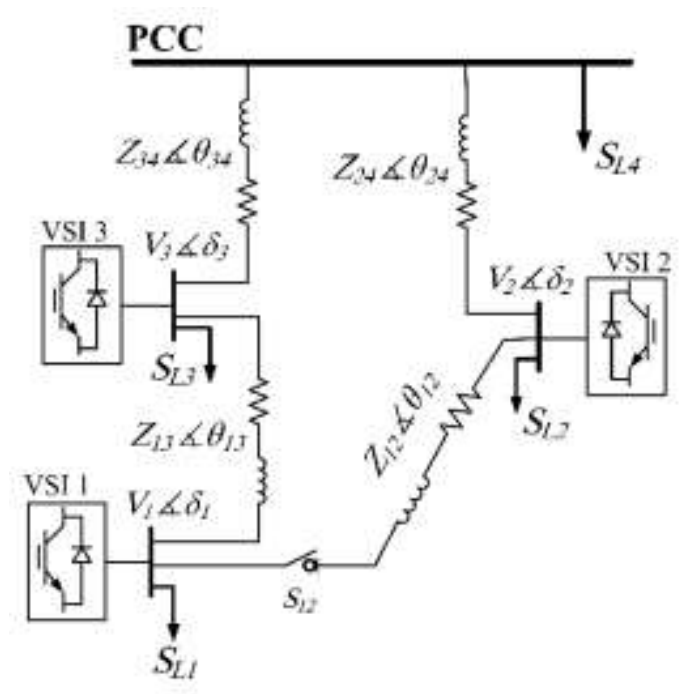

Fig. 6. The simulated MBMG.

Case 1: In this case, all DG units are considered equal in terms of capacity and their contribution in power sharing. The switch $S_{12}$ is open in this case. The simulation results are illustrated in Fig. 7, for conventional and fuzzy consensus-based droop control. Load change is considered as disturbance at $\mathrm{t}=3$ seconds. Despite of the active power sharing which is implemented properly, the reactive power sharing is not implemented precisely via the conventional droop control. The proposed fuzzy consensus control can achieve both accurate active and reactive power sharing, as show in Fig. 7(c) and (d). Performance of the proposed control method is also evaluated when a large disturbance takes place in the MG. DG 2 is switched off and on at $\mathrm{t}=2$ and 4 seconds, respectively, while the control system is stable and accurate reactive power sharing is established. To this end, the consensus terms related to VSI 2 at adjacent controllers must be neglected; otherwise it makes the control system unstable. Moreover, the communication network topology is also effective which is discussed in the discussion section (Section 6). 


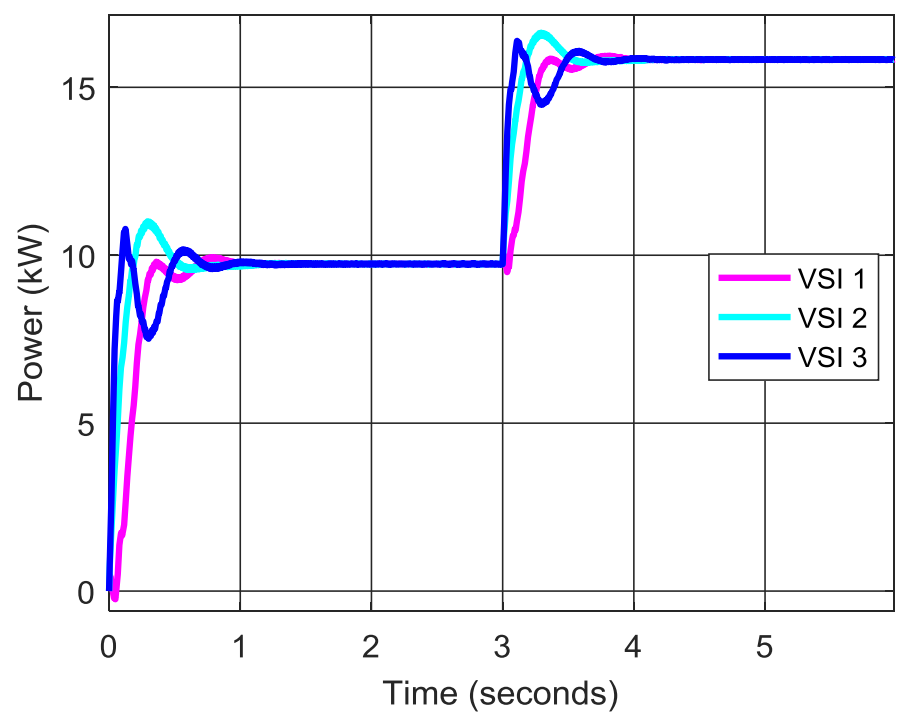

(a)

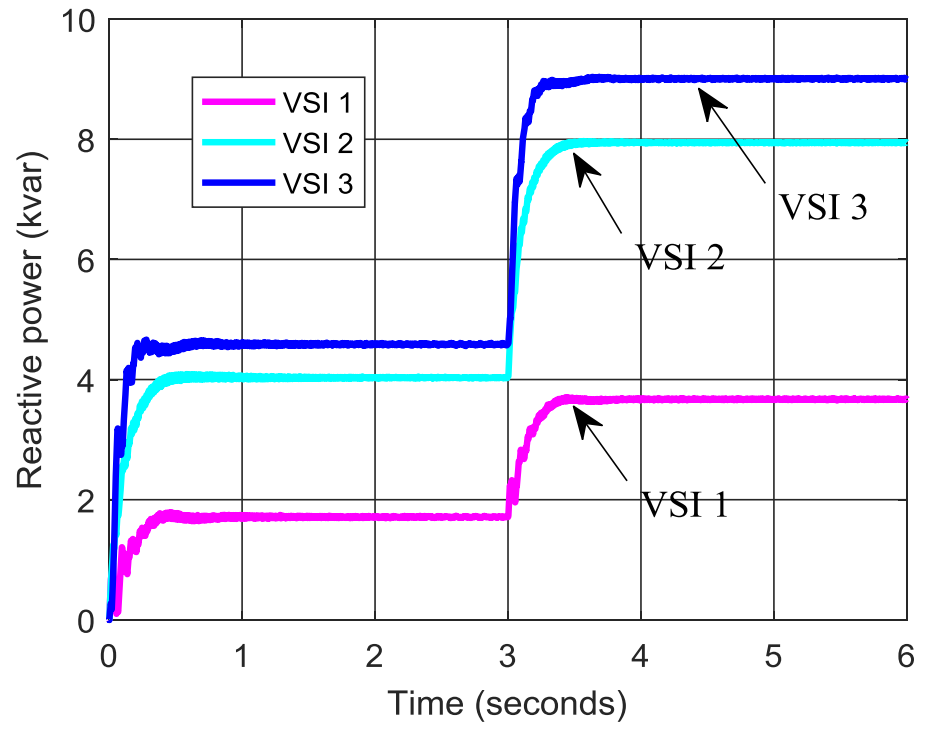

(b) 


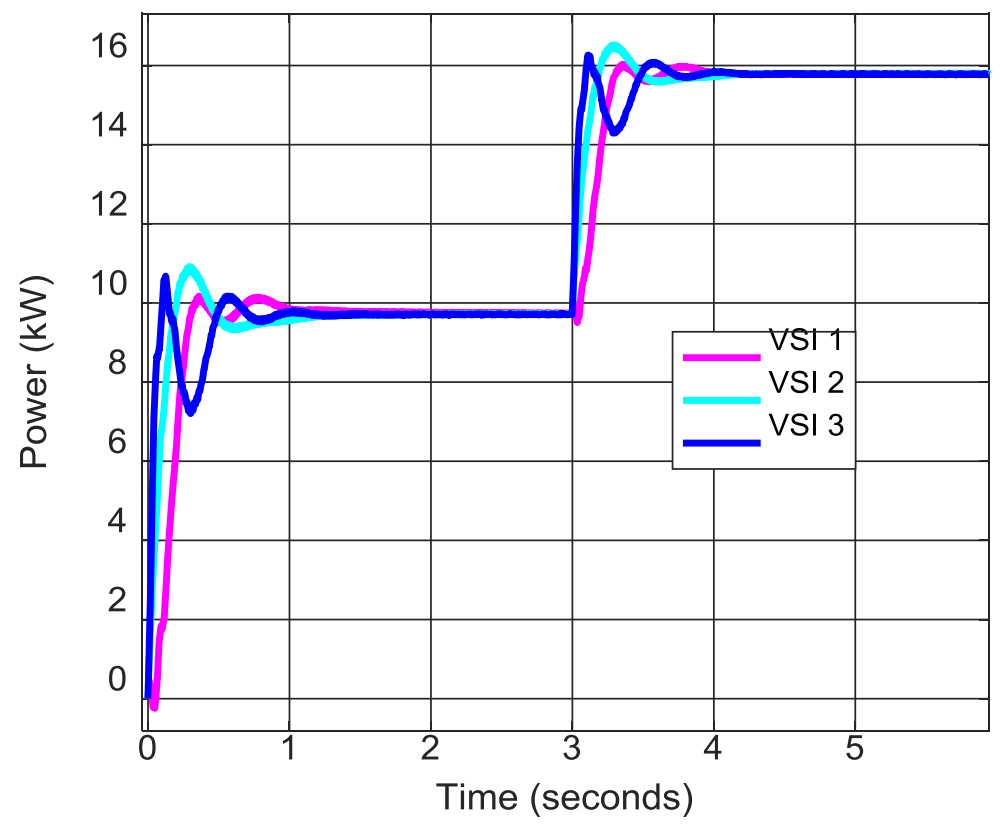

(c)

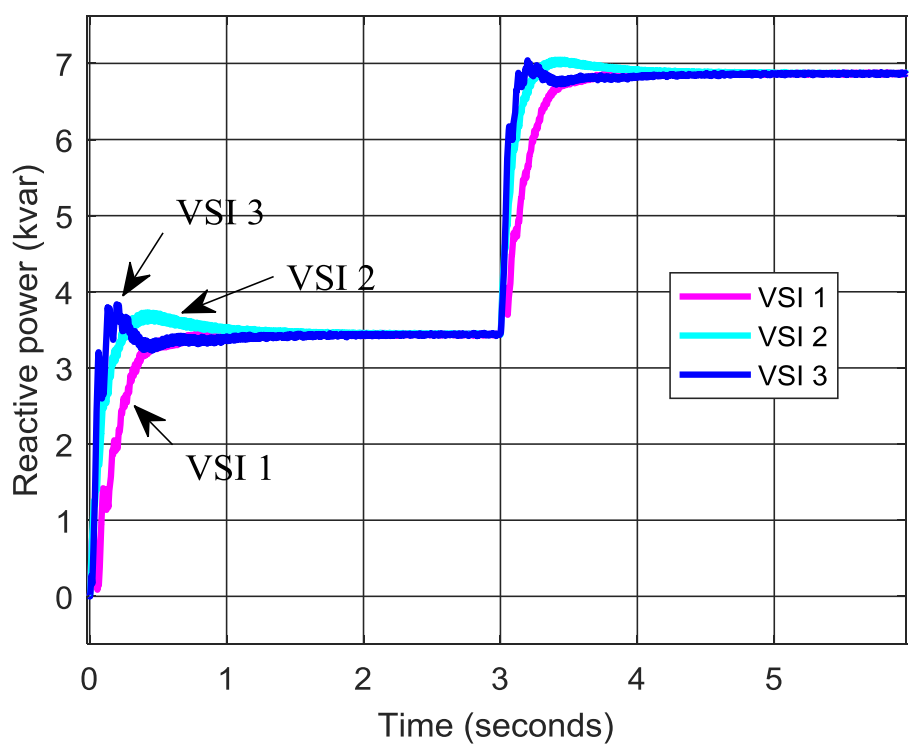

(d) 


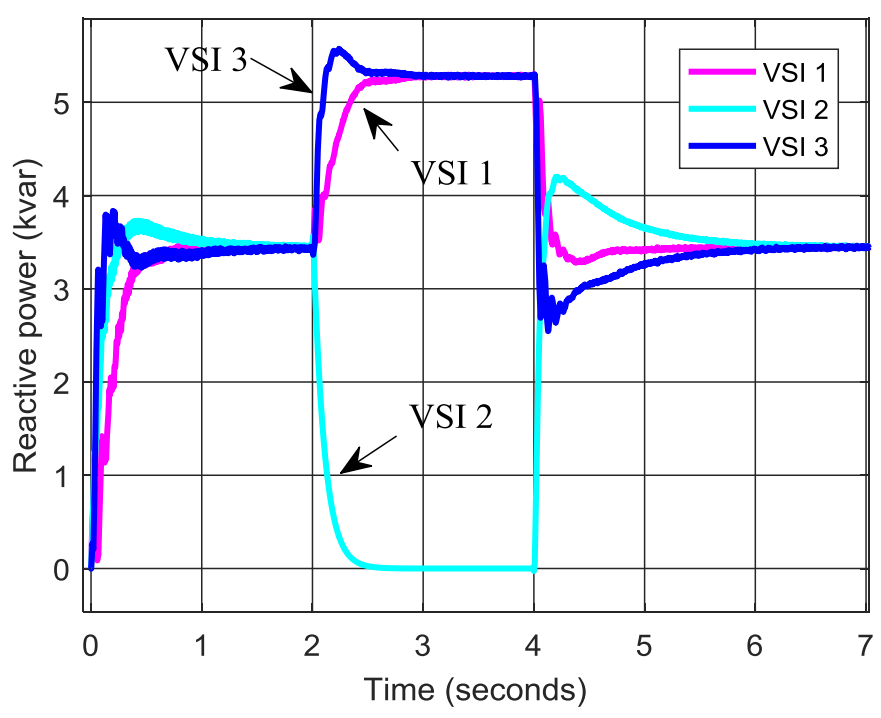

(e)

Fig. 7. The simulated results for Case 1, (a), (b) active and reactive power sharing with the conventional droop control (load change takes place at $\mathrm{t}=3$ as disturbance), (c), (d) active and reactive power sharing with the proposed fuzzy consensus control (load change happens at $\mathrm{t}=3$ as disturbance), (e) reactive power sharing with the proposed fuzzy consensus control when a large disturbance happens (VSI 2 is switched off at $\mathrm{t}=2$ and switched on at $\mathrm{t}=4$ ); reactive power sharing is established properly and the system is stable.

Case 2: In this case, the contribution of DG 1 is twice as those of DG 2 and DG 3 in power sharing. The switch $\mathrm{S}_{12}$ is open. Fig. 8(a) shows performance of the conventional droop control. The contribution of DG 1 is almost zero in supporting the reactive power, because of the larger impedance between DG 1 and load center in comparison to other DG units, which indicates insufficiency of $V-Q$ droop control. On the other hand, the control target is achieved via the proposed fuzzy consensus control, while the $\mathrm{X} / \mathrm{R}$ ratio of the feeders' impedance is one; see Fig. 8(b). The dynamic consensus coefficients obtained from fuzzy controller are shown in Fig. 8(c).

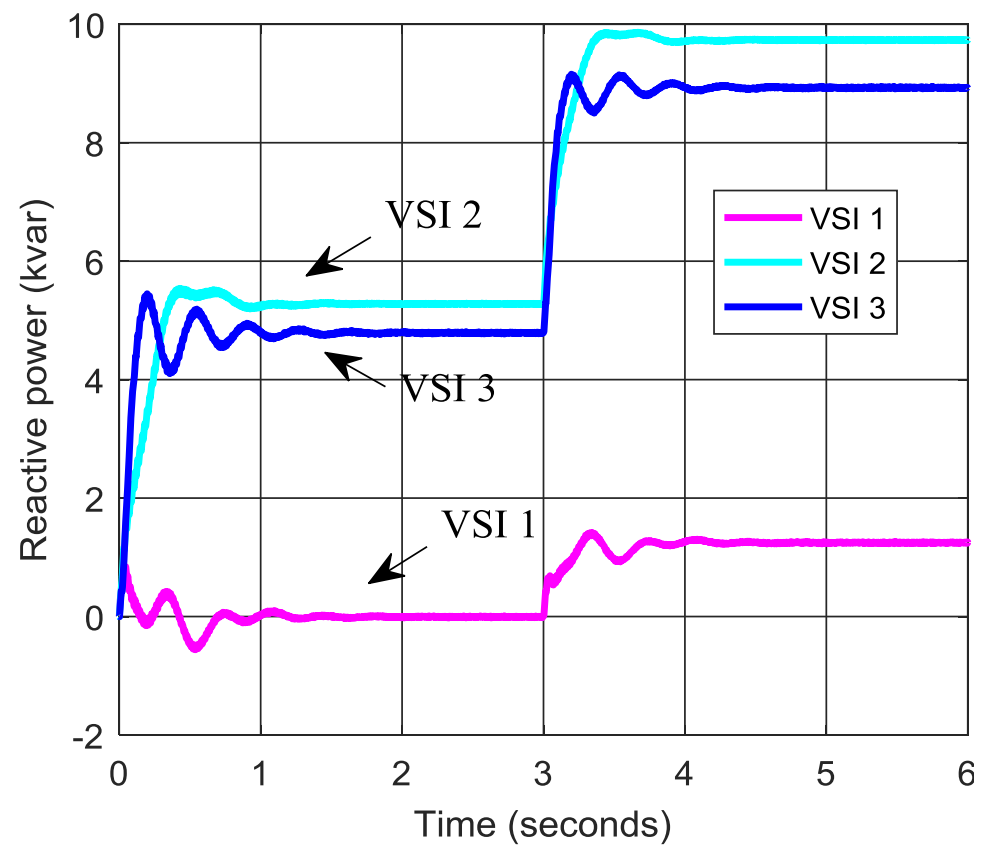


(a)

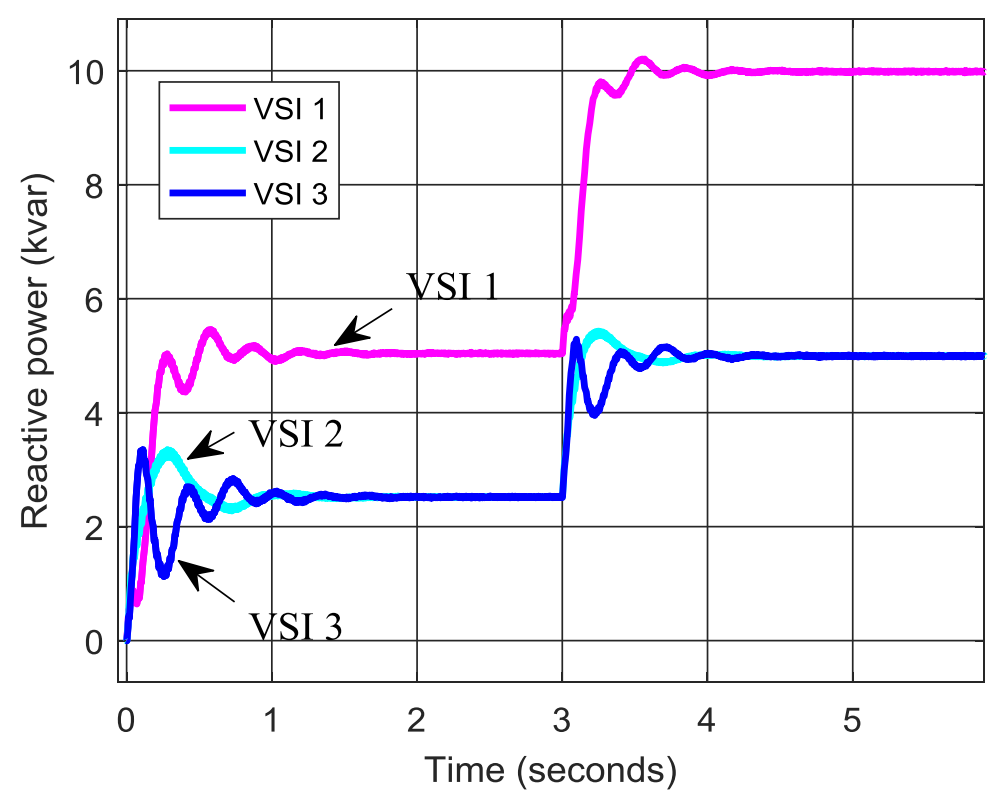

(b)
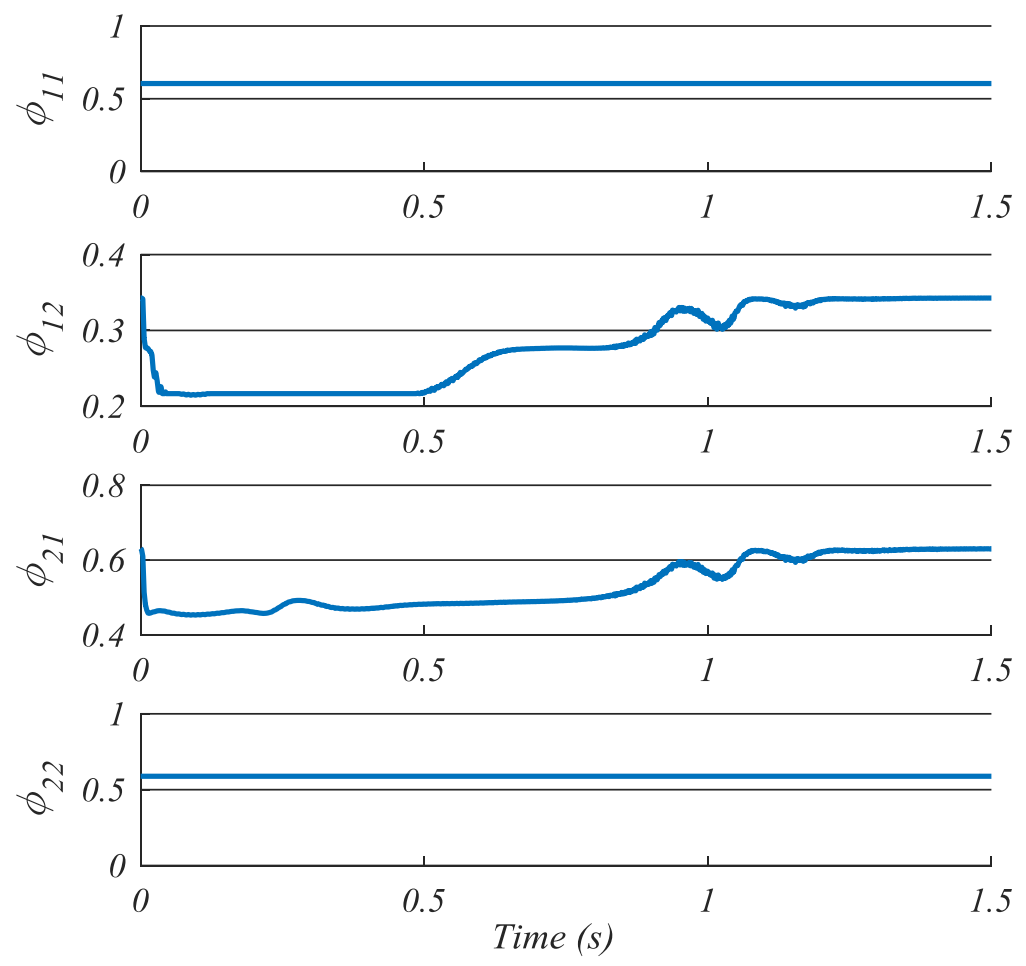

(c)

Fig. 8. The simulated results for Case 2, (a) reactive power sharing with the conventional droop control (load change happens at $\mathrm{t}=3$ as disturbance), (b) reactive power sharing with the proposed fuzzy consensus control (load change happens at $\mathrm{t}=3$ as disturbance), (c) dynamic fuzzy coefficients.

Case 3: In this case, the switch $S_{12}$ is closed to evaluate effectiveness of the proposed method in an MG with meshed topology, which is adopted to improve reliability of the system. Nevertheless, the meshed topology is challenging in terms of control system 
and protection scheme design. Fig. 9 compares the performance of the proposed fuzzy consensus with the conventional droop as well as the conventional consensus control presented in [32]. The unsatisfactory performance of the conventional droop control in reactive power sharing in Fig. 9(a) is improved, to some extent, with the conventional consensus control. Although accurate reactive power sharing is achieved through consensus control, the response time is slow as it takes 3 seconds to establish reactive power sharing. This is because of the cross-coupling effect between $f-P$ and $V$ - $Q$ droop loops in MGs with low X/R ratio. Moreover, the $f-P$ droop loop seeks to alter the phase angle so that the accurate active power sharing is established. While, the phase angle variation inversely influences the reactive power (34), which enforces researchers to adopt $f-Q$ boost loop [19]. As the result, more control effort and more time are needed for reactive power sharing to be achieved precisely. This, in turn, may put power converters to over current situations and also may actuate protective relays. On the other hand, the proposed fuzzy consensus control shows enhanced dynamic performance by taking $\mathrm{X} / \mathrm{R}$ ratio of the feeder impedance into account.

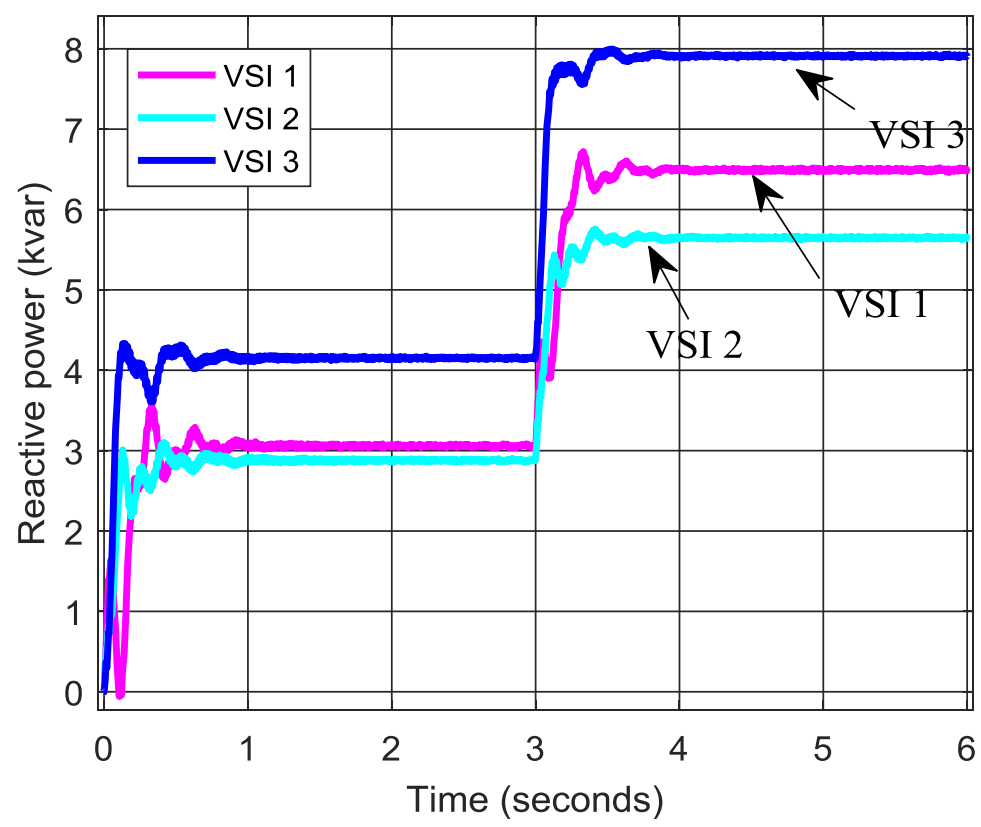

(a) 


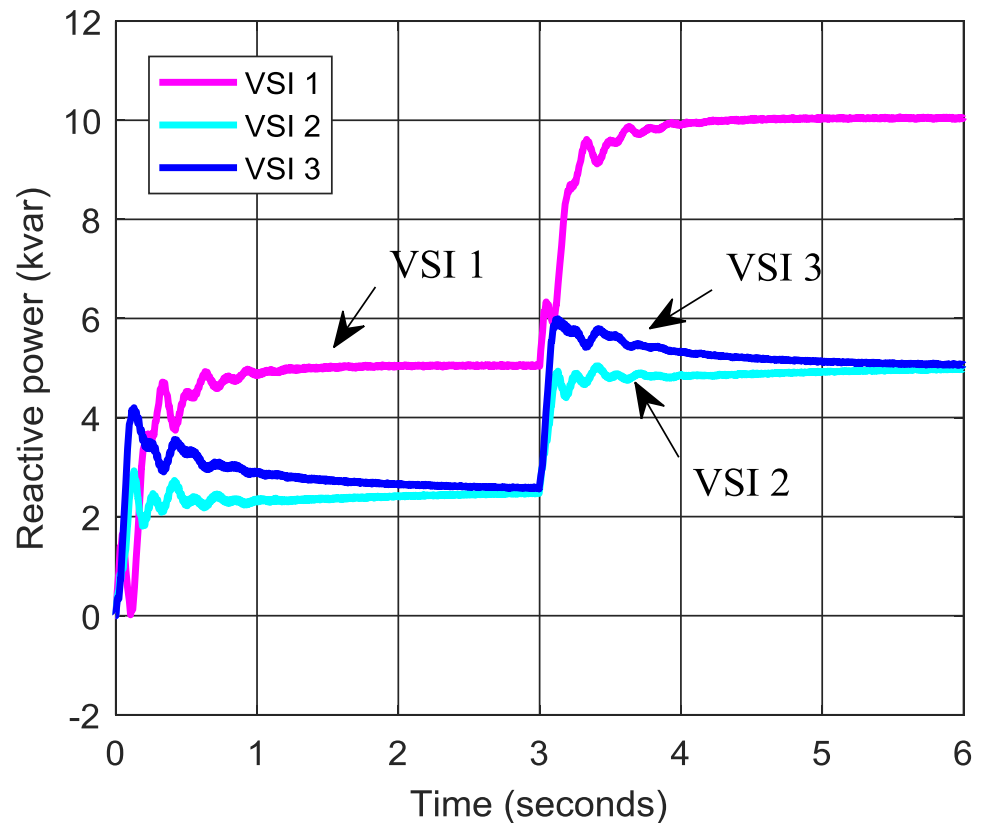

(b)

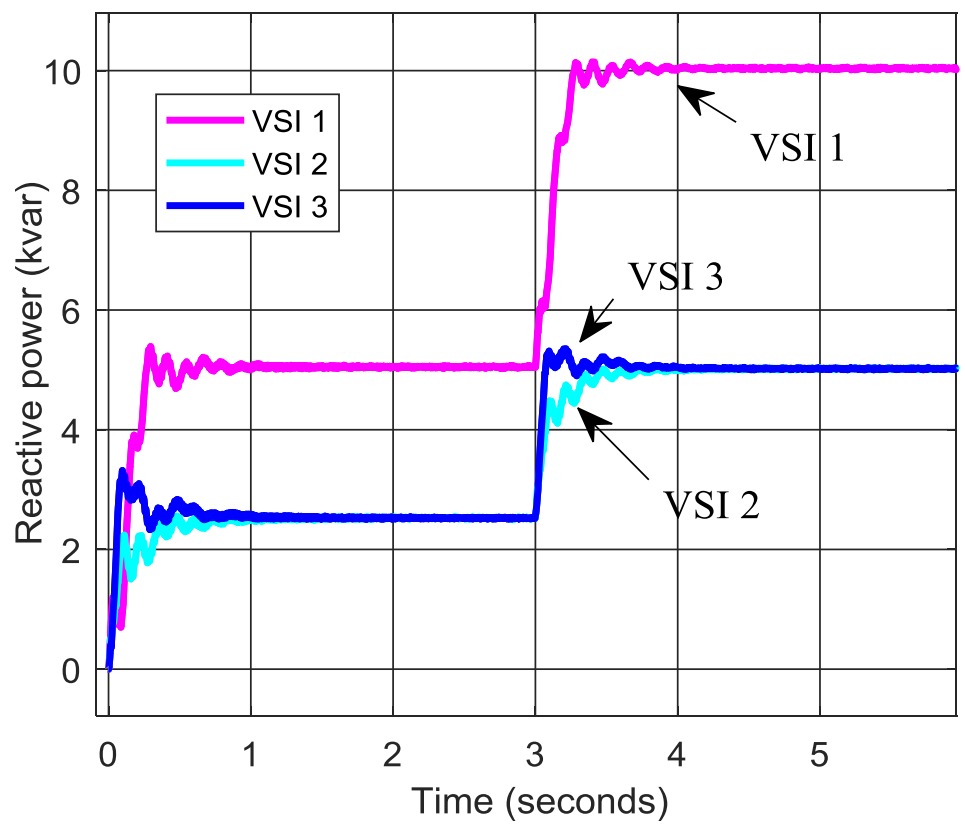

(c)

Fig. 9. The simulated results for Case 3, (a) reactive power sharing with the conventional droop control (load change happens at $\mathrm{t}=3$ as disturbance), (b) reactive power sharing with conventional consensus control (load change happens at $\mathrm{t}=3$ as disturbance), (c) reactive power sharing with the proposed fuzzy consensus control (load change happens at $\mathrm{t}=3$ as disturbance).

\section{DiscuSSION}

In this section, the performance and stability of the proposed method as well as communication links are discussed.

Performance: The insufficiency of the droop control in reactive power sharing is illustrated in Fig. 7 (b) which leads to circulating reactive current between DG units. This, in turn, inflicts electrical losses in the MG and imposes DG units to overloading or even 
instability of the MG (by tripping overload relays). On the other hand, the fuzzy based consensus control system, establishes reactive power sharing accurately, according to the droop gains as shown in Figs 7(d), 8(b) and 9(c). The constant and dynamic fuzzy coefficients are obtained properly to make the control signal consistent with control variables as well as to model the $\mathrm{X} / \mathrm{R}$ ratio of grid impedance as shown in Fig. $8(\mathrm{c})$ (in the case 2 where $\mathrm{X} / \mathrm{R} \approx 1$ ).

Stability: The simulation results prove that the consensus control system is stable as confirmed by Eigen-analysis in Fig. 5. It is expected as the consensus control returns system outputs as feedback into the control system. Although, the method presented in this paper only considers control system performance in the control parameter determination process (as fuzzy gains), the defuzzification of the fuzzy parameters needs stable band of the control parameters to be available. Some control methods, like output feedback control method, may be adopted to determine secure band of the control parameters, which is beyond of the purposes of this paper.

Communication network: in the consensus control, exchanging control signals takes place between adjacent controllers, which demands an uncomplicated communication infrastructure. Nevertheless, the performance of the control system in large disturbances depends on the communication network. For instance, to make the plug-and-play or fault-ride through capabilities feasible in the MG, other DG units must still be connected to the rest of MG through communication links when a DG unit is disconnected from the MG. This issue falls in the communication network design category and a compromise should be made between costs and desirable reliability in the investment process of MG. In Case 1, one DG is switched off to assess the effectiveness of the proposed method in the large disturbance. Although the proposed method satisfies the control targets, it depends on the communication network structure as illustrated in Fig. 10, by a simple example.

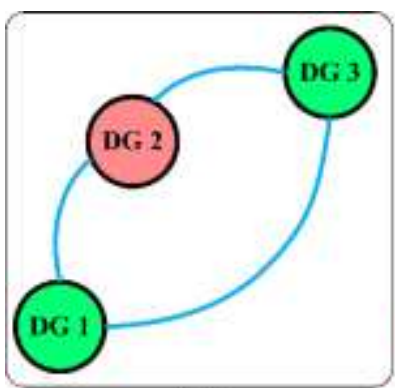

(a)

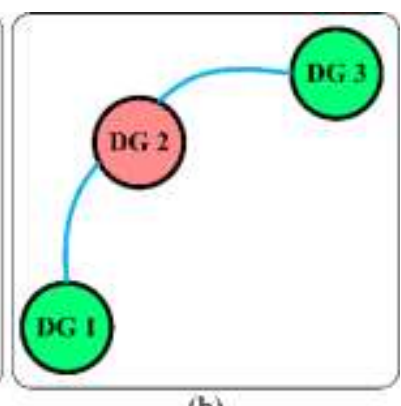

(b)

Fig. 10. A simple example on the impact of communication network topology on the performance of consensus controller when a DG unit is disconnected from the MG, (a) the control system would be stable if DG 2 is disconnected, provided that the consensus signals from DG 2 are also disconnected from DG 1 and DG 3, (b) the control system would not be stable if DG 2 is disconnected, unless a bypass is provided to connect consensus signals from DG 1 to DG 3 through DG 2.

\section{Conclusion}

In this paper, a novel fuzzy-consensus control system is proposed for accurate power sharing for islanded MBMGs where conventional $f-P$ and $V-Q$ control cannot be decoupled. In the presented method, consensus signals are designed by adopting 
dynamic fuzzy parameters which reflect the power network impedance into the controller. The related fuzzy coefficients are adjusted considering the $\mathrm{X} / \mathrm{R}$ ratio of the interconnecting power lines and the permitted band of frequency and voltage variation. The fuzzy interface system with three inputs and four dynamic outputs as well as related rule table are presented in the paper in detail. A novel small signal model for MBMGs is also developed to assess the stability and performance of the closed loop system. The power network is incorporated to model the $f-P$ and $V-Q$ control loops properly. The eigenvalue loci of the developed state matrix showed unstable region in relation to the power network impedance. Finally, consensus control is modeled in the small signal model to analyze the stability of the proposed control system. Simulation results in MATLAB/Simulink, prove the effectiveness of the proposed control system. In a general view, fuzzy consensus control provides accurate power sharing with desirable dynamic performance in MGs and improves the stability, however, in comparison to easy implementation of conventional droop control, it enforces some extra costs and complexity to the control system.

\section{References}

[1] do Nascimento, Vinícius Cabral, Germano Lambert-Torres, Claudio Inacio de Almeida Costa, and Luiz Eduardo Borges da Silva. "Control model for distributed generation and network automation for microgrids operation." Electric Power Systems Research 127 (2015): 151-159.

[2] M. H. Moradi, M. Eskandari, P. Siano, "Safe transition from connection mode to islanding mode in Microgrids", IEEE, Electrical Engineering (ICEE), 2016 24th Iranian Conference on, pp. 1902-1907, May. 2016.

[3] C. K. Sao and P. W. Lehn, “Control and power management of converter fed microgrids,” IEEE Trans. Power Syst., vol. 23, no. 3, pp. 1088-1098, Aug. 2008.

[4] J. M. Guerrero, J. C. Vasquez, and J. Matas, "Hierarchical control of droop-controlled AC and DC microgrids-A general approach toward standardization,” IEEE Trans. Ind. Electron., vol. 58, no. 1, pp. 158-172, Jan. 2011.

[5] D. E. Olivares et al., "Trends in microgrid control," IEEE Trans. Smart Grid, vol. 5, no. 4, pp. 1905-1919, Jul. 2014.

[6] M. H. Moradi, M. Eskandari, S. M. Hosseinian, "Operational Strategy Optimization in an Optimal Sized Smart Microgrid", IEEE Trans. Smart Grid, vol. 6, no. 3, pp. 1087-1095, May. 2015.

[7] M. H. Moradi, M. Eskandari, "A Hybrid method for Simultaneous optimization of DG capacity and Operational Strategy in Microgrids considering uncertainty in electricity price forecasting," Renewable Energy 2014, 68, 697 -714.

[8] Chen, Meng, and Xiangning Xiao. "Hierarchical frequency control strategy of hybrid droop/VSG-based islanded microgrids." Electric Power Systems Research 155 (2018): 131-143.

[9] Liu, Wei, Wei Gu, Yinliang Xu, Yong Wang, and Kaifeng Zhang. "General distributed secondary control for multi-microgrids with both PQ-controlled and droop-controlled distributed generators." IET Generation, Transmission \& Distribution 11, no. 3 (2017): 707718.

[10] M. H. Moradi, M. Eskandari, S. M. Hosseinian, "Cooperative control strategy of energy storage systems and micro sources for stabilizing microgrids in different operation modes," International Journal of Electrical Power \& Energy Systems, vol. 6, pp. 390-400, June. 2016.

[11] Tavakoli, Saman Dadjo, Mohammad Mahdavyfakhr, Mohsen Hamzeh, Keyhan Sheshyekani, and Ebrahim Afjei. "A unified control strategy for power sharing and voltage balancing in bipolar DC microgrids." Sustainable Energy, Grids and Networks 11 (2017): 5868.

[12] F. Katiraei and M. R. Iravani, "Power management strategies for a microgrid with multiple distributed generation units," IEEE Trans. Power Syst., vol. 21, no. 4, pp. 1821-1831, Nov. 2006. 
[13] J. Rocabert, A. Luna, F. Blaabjerg, and P. Rodríguez, "Control of power converters in AC microgrids," IEEE Trans. Power Electron, vol. 27, no. 11, pp. 4734-4749, Nov. 2012.

[14] M. C. Chandorkar, D. M. Divan, and R. Adapa, “Control of parallel connected inverters in standalone AC supply systems," IEEE Trans. Ind. Appl., vol. 29, no. 1, pp. 136-143, Jan1993.

[15] F Dheer, Dharmendra Kumar, Nimish Soni, and Suryanarayana Doolla. "Improvement of small signal stability margin and transient response in inverter-dominated microgrids." Sustainable Energy, Grids and Networks 5 (2016): 135-147.

[16] Krismanto, Awan Uji, N. Mithulananthan, and Olav Krause. "Stability of Renewable Energy based Microgrid in Autonomous Operation." Sustainable Energy, Grids and Networks 13 (2018): 134-147.

[17] Sadabadi, Mahdieh S., Qobad Shafiee, and Alireza Karimi. "Plug-and-play voltage stabilization in inverter-interfaced microgrids via a robust control strategy." IEEE Transactions on Control Systems Technology 25, no. 3 (2017): 781-791.

[18] J. M. Guerrero, J. Matas, L. G. de Vicuña, M. Castilla, and J. Miret, "Decentralized control for parallel operation of distributed generation inverters using resistive output impedance,” IEEE Trans. Ind. Electron., vol. 54, no. 2, pp. 994-1004, Apr. 2007.

[19] Egwebe, Augustine M., Meghdad Fazeli, and Paul Holland. "Adaptive virtual resistance load sharing for resistive microgrids." Electric Power Systems Research 160 (2018): 17-26.

[20] Vandoorn, Tine L., Bart Meersman, Lieven Degroote, Bert Renders, and Lieven Vandevelde. "A control strategy for islanded microgrids with dc-link voltage control." IEEE Transactions on Power Delivery, vol. 26, no. 2, 703-713, 2011.

[21] P. H. Divshali, A. Alimardani, and S. H. Hosseinian, "Decentralized cooperative control strategy of microsources for stabilizing autonomous VSC-based microgrids," IEEE Trans. Power Syst., vol. 24, no. 4, pp. 1949-1959, Nov. 2012.

[22] Y. W. Li and C.-N. Kao, "An accurate power control strategy for power-electronics-interfaced distributed generation units operating in a low-voltage multibus microgrid," IEEE Trans. Power Electron., vol. 24, no. 12, pp. 2977-2988, Dec. 2009.

[23] Sadeghian, Mohamad, and Bahador Fani. "Advanced localized reactive power sharing in microgrids." Electric Power Systems Research 151 (2017): 136-148.

[24] Y. A-R. I. M, E. F. El-Saadany, “Adaptive Decentralized Droop Controller to Preserve Power Sharing Stability of Paralleled Inverters in Distributed Generation Microgrids,” IEEE Trans. Power Electron, vol. 23, no. 6, pp. 2806-2816, Nov 2008.

[25] W. Yao, M. Chen, J. Matas, M. Guerrero, and Z. Qian, "Design and analysis of the droop control method for parallel inverters considering the impact of the complex impedance on the power sharing," IEEE Trans. Ind. Electron., vol. 58, no. 2, pp. 576-588, Feb. 2011.

[26] J. He, Y. W. Li, J. M. Guerrero, F. Blaabjerg, and J. C. Vasquez, “An Islanding Microgrid Power Sharing Approach Using Enhanced Virtual Impedance Control Scheme,” IEEE Transactions on Power Electronics, vol. 28, no. 11, pp. 5272-5282, Nov. 2013.

[27] H. Mahmood, D. Michaelson, and J. Jiang, "Accurate reactive power sharing in an islanded microgrid using adaptive virtual impedances,” IEEE Trans. Power Electron, vol. 30, no. 3, pp. 1605-1617, Mar. 2015.

[28] H. Han, Y. Liu, Y. Sun, M. Su, J. M. Guerrero, “An Improved Droop Control Strategy for Reactive Power Sharing in Islanded Microgrid,” IEEE Trans. Power Electron, vol. 30, no. 6, pp. 3133-3141, June. 2015.

[29] M. Eskandari, L. Li and M. H. Moradi, "Decentralized Optimal Servo Control System for Implementing Instantaneous Reactive Power Sharing in Microgrids," in IEEE Transactions on Sustainable Energy, vol. 9, no. 2, pp. 525-537, April 2018.

[30] Schiffer, Johannes, Thomas Seel, Jörg Raisch, and Tevfik Sezi. "Voltage Stability and Reactive Power Sharing in Inverter-Based Microgrids With Consensus-Based Distributed Voltage Control." IEEE Trans. Contr. Sys. Techn. 24, no. 1 (2016): 96-109.

[31] H. Zhang, S. Kim, Q. Sun, J. Zhou, "Distributed Adaptive Virtual Impedance Control for Accurate Reactive Power Sharing Based on Consensus Control in Microgrids,” IEEE Trans. Smart Grid, vol. 6, no. 3, pp. 1087-1095, May. 2016.

[32] J. W. Simpson-Porco, Q. Shafiee, F. D"orfler, J. M. Vasquez, J. M. Guerrero, and F. Bullo, "Secondary frequency and voltage control of islanded microgrids via distributed averaging," IEEE Transactions on Industrial Electronics, vol. 62, no. 11, pp. 7025-7038, 2015.

[33] Lin-Yu Lu, Chia-Chi Chu, "Consensus-Based Droop Control Synthesis for Multiple DICs in Isolated Micro-Grids," IEEE Trans. Power Syst., vol. 30, no. 5, pp. 2243-2256, Sep. 2015.

[34] M. Eskandari and L. Li, "A novel small signal model of multi-bus microgrids for modeling interaction of droop controllers through the power network," 2017 20th International Conference on Electrical Machines and Systems (ICEMS), Sydney, NSW, 2017, pp. 16. 
[35] Pulcherio, Mariana C. at el. "Evaluation of control methods to prevent collapse of a mixed-source microgrid." IEEE Transactions on Industry Applications 52, no. 6 (2016). 